\title{
Vientos del sur. El valle de Yocavil (Noroeste Argentino) bajo la dominación incaica
}

\author{
Luis R. GonZÁLEZ ${ }^{1}$ Y Myriam N. TARRAGÓ ${ }^{2}$
}

\begin{abstract}
RESUMEN
El sector meridional del valle de Yocavil (provincia de Catamarca) conformó un espacio de importancia estratégica y económica para la administración incaica. En este artículo repasamos la información arqueológica relacionada con la dominación imperial, la cual fue producida durante nuestras investigaciones en el área. A partir de las mismas, se constata una diferencial distribución y volumen de evidencias, lo que interpretamos como resultado de la dialéctica entre los intereses específicos del Estado cusqueño y las cualidades de la organización política, económica y del sistema de representaciones de las sociedades complejas que poblaban el valle.
\end{abstract}

Palabras claves: valle de Yocavil - dominación incaica sociedades complejas.

\section{ABSTRACT}

The southern part of the Yocavil valley (Province of Catamarca, Argentina) was of strategic and economic importance for the Inca State. This paper revises the archaeological data obtained from our research in the area in connection to imperial rule, to reveal the differential distribution and volume of evidence. We consider this the result from the dialectic relationship between interests specific to the cusquean State, and the political and economical organizational qualities of the complex societies that inhabited the valley, including their system of representations.

Key words: Yocavil valley - Inca rule - complex societies. Recibido: abril 2004. Manuscrito revisado aceptado: agosto 2004.

\section{Introducción}

El sector meridional del valle de Yocavil, en la provincia de Catamarca, fue, a partir del siglo IX, el escenario de dinámicos procesos sociales, con

1 Departamento de Ciencias Antropológicas, Facultad de Filosofía y Letras, Universidad de Buenos Aires. Moreno 350 (1091), Buenos Aires, ARGENTINA. Email: zangolez@yahoo.com el surgimiento y consolidación de complejas y extensas formaciones sociopolíticas. A la hora de su incorporación al Tawantinsuyu, a comienzos del siglo XV, para los administradores estatales la región acreditaba suficiente relevancia estratégica y económica como para invertir esfuerzos en su control. Sugestivamente, la ocupación incaica en el área se encontraba pobremente registrada cuando, hace 17 años, comenzamos a desarrollar investigaciones en el sector del valle comprendido entre Fuerte Quemado y Punta de Balasto (Figura 1).

Tales investigaciones nos han permitido obtener datos sobre la presencia imperial que no encuadran en los criterios "monumentalistas" (C. González 1996: 34) generalmente utilizados para evaluar el grado y las características de la dominación cusqueña en los Andes Meridionales. Sugieren, además, que un exceso de atención a tales criterios puede no sólo constituir un obstáculo para capturar las evidencias más sutiles de la presencia imperial, sino también enturbiar el análisis de la articulación entre la organización estatal con sus aspiraciones y las sociedades locales con sus estrategias de resistencia. En tal sentido, el propósito de este artículo es, en primer lugar, repasar las evidencias incaicas en el área bajo estudio. En segundo lugar, proponemos una interpretación de tales evidencias en el marco del conflicto inherente al enfrentamiento de los objetivos cusqueños con las respuestas de la organización sociopolítica local.

\section{Organización social y actividades productivas en el sur del valle de Yocavil}

A partir del siglo IX el valle de Yocavil meridional comenzó a transformarse en uno de los paisajes más densamente poblados del Noroeste Argen-

2 CONICET. Museo Etnográfico Juan B. Ambrosetti, Facultad de Filosofía y Letras, Universidad de Buenos Aires. Moreno 350 (1091), Buenos Aires, ARGENTINA. Email: mtarrago@mail.retina.ar 


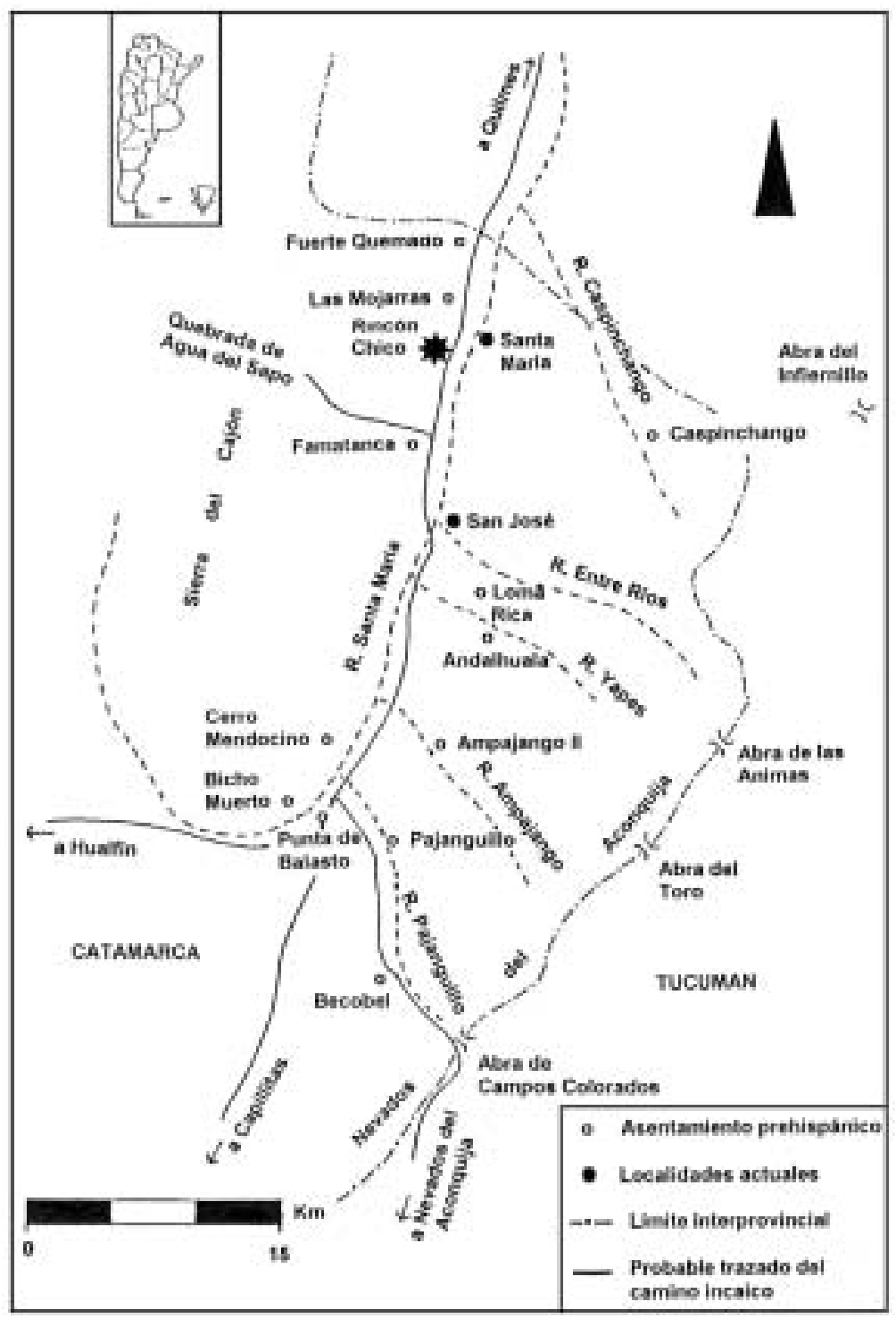

Figura 1. Sur del valle de Yocavil, Argentina.

tino prehispánico. Con el correr del tiempo, se erigieron numerosos asentamientos de diferentes características y magnitudes y cientos de hectáreas de terreno fueron habilitadas para las actividades agropecuarias. La geomorfología del área otorgó un marco específico a las modalidades de ocupación del espacio y a la organización de las actividades productivas. El sector meridional, con una altitud media entre los 1900 y 2100 m.snm y condiciones ambientales áridas a semiáridas con escasas precipitaciones, está recorrido de sur a norte por el río Santa María. Hacia el este del acuífero, el relieve se presenta como una amplia franja de niveles aterrazados que conducen hasta la elevada cadena de los Nevados del Aconquija. $\mathrm{Al}$ oeste, en cambio, casi desde la vera del río se presentan extensos conos de deyección que se acumulan en el piedemonte de la cercana Sierra del Cajón (González y Tarragó 2000 Ms). Los principales afluentes del río Santa María son los que provienen de las vertientes occidentales de la Sierra del Aconquija, como el Caspinchango, Entre Ríos, Andalhuala y Ampajango. La Sierra del Cajón, por su parte, no ofrece colectores de curso permanente, aunque se tiene información sobre ojos de agua, en su mayoría secos en la actualidad, en los sectores altos. A occidente del río los grandes poblados aglomerados indígenas se fun- 
daron en puntos altos de las serranías y sus piedemontes, siendo los más conocidos Quilmes, Fuerte Quemado, Las Mojarras, Rincón Chico y Cerro Mendocino. Las condiciones ambientales permitieron el sostenimiento bajo riego de cultivos mesotérmicos de buen rendimiento (maíz, poroto, ají y zapallo) y estos poblados habrían aprovechado a tal fin la estrecha llanura aluvial del río Santa María. Se contaba, además, con pastizales de altura aptos para el pastoreo de camélidos, mientras que en el fondo de valle prosperaron especies arbóreas valiosas por sus maderas y frutos. $\mathrm{Al}$ oriente del río los asentamientos conglomerados se ubicaron relativamente alejados del fondo del valle, en mesetas o quebradas altas, como en La Maravilla-Masao, Pabellón, Loma de Jujuil, Loma Rica de Shiquimil, Andalhuala, Ampajango y Pajanguillo. En estos casos, la producción agrícola se fundamentó en los campos de cultivo habilitados en las cercanías de los ríos de aguas permanentes antes mencionados.

La paulatina consolidación de sociedades jerarquizadas con distintos grados de control político regional derivó en una articulación de los asentamientos según diferentes niveles. Como ejemplo, vale mencionar que los cronistas que integraron los ejércitos españoles que "pacificaron" el valle dejaron constancia que, por lo menos en el momento final del proceso indígena, el núcleo de Quilmes tenía a 11 pueblos bajo su control (Lorandi y Boixadós 1988: 345; Tarragó 2000: 274-275). Para el suroeste del área se ha propuesto que el asentamiento de Rincón Chico asumió la primacía dentro de un sistema de complementariedad funcional para la obtención directa de los recursos básicos para la subsistencia, el cual integraba a diversas instalaciones, tanto vinculadas con el pastoreo y emplazadas al interior de la Sierra del Cajón como dedicadas a cultivos intensivos en las cuencas de aguas permanentes orientales (González y Tarragó 2000 Ms).

En forma paralela, las cabeceras políticas parecen haber desarrollado extensas redes de interacción, mediante las cuales determinados bienes, en particular las artesanías de prestigio identificadas con el conocido estilo "santamariano", tuvieron la oportunidad de llegar a territorios tan distantes como las provincias de Cuyo, Patagonia y el norte de Chile. Como parte del proceso de la institucionalización de las desigualdades sociales y la consolidación de las minorías político-reli- giosas, se ha propuesto que estas redes de interacción a larga distancia fueron centralizadas por los segmentos sociales de élite, los cuales, además de controlar la producción y la distribución de los recursos de subsistencia, edificaron un sistema de representaciones dominante que contribuía a reproducir las condiciones materiales de existencia de las comunidades. La diferenciación social interna y la escala de la interacción a larga distancia tuvieron serias consecuencias para la organización de las actividades productivas, auspiciando la elaboración de bienes valorizados y la consolidación de cuerpos de mano de obra especializada (Tarragó et al. 1997: 236-237; L. González 2001).

La cerámica y los metales fueron enriquecidos con el plus simbólico materializado en la conocida iconografía santamariana. Las urnas funerarias son las piezas más conocidas de la región y, asimismo, las de mayor tamaño y mayor potencia expresiva, a través de su compleja decoración pintada y modelada (Tarragó 2000: 282-284). La alfarería santamariana clásica se presenta en los asentamientos de Yocavil acompañada, en proporciones minoritarias pero regulares, por escudillas correspondientes al tipo Famabalasto Negro Grabado. A partir de su discreta distribución espacial, es probable que se trate de un estilo originario del valle. De superficie y matriz oscura, pastas finas y motivos decorativos plasmados por incisión, se ha planteado que esta cerámica conformó un puente material y simbólico entre los ceramistas y los metalurgistas y que habría estado vinculada a los desempeños ceremoniales (González y Tarragó 2003). En cuanto a los metales, los temas del estilo santamariano se concentran en un puñado de motivos dominantes. Los objetos de bronce más sobresalientes son las placas, las campanas ovales y las hachas con mango incorporado, una trilogía que fue parte sustancial en el ceremonialismo prehispánico tardío (González y Cabanillas 2004).

Sobre esta organización sociopolítica, económica y espacial, el Estado impuso sus propios principios, integrando a la región dentro de la provincia de Quire-Quire y que fuera destacada en las crónicas por su producción maicera, la cual permitió sostener a los ejércitos de Diego de Almagro por un tiempo prolongado. El territorio vallisto acreditaba, por lo menos, dos aspectos de importancia para los intereses cuzqueños. En primer lugar, 
constituía un corredor natural para las comunicaciones entre las tierras altas puneñas y la región valliserrana del Noroeste Argentino, conectando el corazón del Imperio con sus dominios más australes. Un tramo principal del Qhapaqñan, con diversos ramales secundarios, recorría el fondo del valle uniendo importantes postas imperiales.

En segundo lugar, las sofisticadas organizaciones productivas existentes al momento de la llegada imperial podían ser reorientadas hacia los requerimientos estatales a bajo costo. Por una parte, podía aprovecharse la entrenada mano de obra disponible y, por otra, la organización sociopolítica vigente le posibilitaba al Imperio implementar una dominación indirecta, a través de la captación de los líderes locales como agentes del Estado. En este sentido, no sólo habría sido de interés el aprovechamiento de los extensos sistemas agrícolas en operación, sino también la ocupación y el redimensionamiento de los talleres metalúrgicos montados y atendidos por mano de obra especializada (L. González 2002).

Hasta nuestros trabajos, en la literatura arqueológica solían consignarse como asociados al momento imperial en la zona de investigación sólo a los asentamientos de Fuerte Quemado y de Punta de Balasto (p.e., Raffino 1981, 1988; Williams 1994; Williams y D'Altroy 1998). Estas instalaciones se ubican en los bordes del sector que acotáramos, la primera al norte y la segunda al sur, en la entrada (o salida) del valle. Tal situación, al sostener implícitamente una ausencia incaica en el espacio de casi $50 \mathrm{~km}$ que media entre ambos asentamientos, cerraba los caminos para avanzar en el análisis tanto de los objetivos y estrategias de dominación cusqueña en la región como de las respuestas materiales y simbólicas elaboradas por las sociedades locales. Desde nuestra postura, el conocimiento existente escondía un vacío de información derivado de metodologías de estudio basadas en rígidas categorizaciones de rasgos impuestas al registro arqueológico, en particular el arquitectónico, para estimar el grado de presencia imperial. Como alertaron otros autores (Morris 1988: 243-244; Meyers 1999: 244), las manifestaciones arqueológicas estimadas como "típicas" para señalar dicha presencia, en el extenso territorio del Tawantinsuyu parecen no haber sido tan uniformes como muchas veces se ha supuesto, lo que hace que, con frecuencia, sean apenas detectables en contextos dominados por elementos culturales nativos. Sería presumible que lo "atípico" adquiriera aún mayor representación en regiones fronterizas y alejadas del Cuzco y, sobre todo, pobladas por complejas organizaciones sociopolíticas, como puede ser encuadrado nuestro caso de estudio.

Al respecto, partimos de considerar que en el proceso de dominación imperial de la región pesaron no sólo las aspiraciones estratégicas y económicas del Estado, sino también las particulares condiciones bajo las cuales se articularon las organizaciones sociopolíticas locales y la estatal. De tal modo, los intereses cuzqueños y los de las élites regionales ya establecidas participaron de una dinámica compleja dentro de la cual la administración dominante pudo juzgar operativo mantener algunos elementos de la organización preexistente y los grupos de poder locales pudieron conservar relativa autonomía en ciertos aspectos materiales y simbólicos. Esta dinámica se manifestaría desde lo arqueológico en una más o menos amplia variabilidad en la jerarquía de los indicadores tradicionalmente atendidos para definir la presencia imperial. Si bien un registro arqueológico incaico "rico" puede estar sugiriendo un particular interés cusqueño por el espacio involucrado, la situación inversa no debería ser asumida como evidencia de que un territorio haya estado sujeto a una ocupación marginal.

Recientemente dimos a conocer un conjunto de datos, incluyendo fechados radiocarbónicos, que sugieren que la ocupación imperial en el sur del valle de Yocavil fue bastante más intensa que lo tradicionalmente reconocido, pero con un reflejo arqueológico de alta variabilidad (González y Tarragó 2000 Ms, 2003; Tarragó et al. 2000 Ms, $2001 \mathrm{Ms})$. Veamos de más cerca como se distribuyen las evidencias que nos hablan de dicha ocupación.

\section{Presencia inca en el sur del valle de Yocavil}

\section{Fuerte Quemado}

El asentamiento de Fuerte Quemado se ubica a 7 $\mathrm{km}$ al norte de la ciudad de Santa María y abarca distintos sectores, con construcciones en cerros, laderas y llanura aluvial. Las primeras descripciones se remontan a fines del siglo XIX y principios del XX (Ten Kate 1896; Quiroga 1901; Lafone Quevedo 1904; Bruch 1911), las que documenta- 
ron varios conjuntos de construcciones. Los restos principales se registraron en el cerro La Ventanita o Intihuatana, mientras que otros de similar relevancia, ubicados a unos $2 \mathrm{~km}$ al sur, se encuentran hoy muy destruidos por la construcción de un "Calvario". Al parecer, el difundido plano de Ten Kate (1896: Fig. 27) correspondería a esta segunda instalación, así como el croquis de Quiroga (1901: 239) de acuerdo a la revisión realizada por Kriscautzky (1999). En la cumbre del morro, según Quiroga, se encontraban cuatro grandes menhires tumbados, el más largo de $2 \mathrm{~m}$ con tallado en ambas caras. Respecto de estos hallazgos, Quiroga (1901: 242) expresó: "Los cuatro menhires pueden haber sido un observatorio solar, los que señalarían los cuatro puntos cardinales, indicando además las diversas estaciones del año, por la dirección y largo de la sombra proyectada".

En cuanto al sector La Ventanita, Lafone Quevedo (1904) lo visitó en 1886, observando en la cumbre un conjunto de estructuras de características especiales, lo que lo llevó a plantear la existencia de un reloj solar conformado por un eje noroestesureste, tangente a un círculo o torre oriental y al paso o "puerta" entre cuatro pilares (Lafone Quevedo 1904: 128). El plano de Bruch (1911: Fig. 39), levantado con posterioridad, corroboró el croquis de Lafone Quevedo, brindando una planta de la estrecha cumbre del cerro, rodeada por un muro perimetral y dotada de una vía de acceso escalonada con lajas a tramos regulares (Figura 2). En este lugar, asimismo, se habrían encontrado emplazados los tres torreones ilustrados por Methfessel a fines del siglo XIX (Raffino 1988: 28), los que contaban con aberturas de ingreso y lajas dispuestas a modo de escalones. Se indicó que se usaron lajas afirmadas con argamasa y que en algunos sectores se conservaba un revoque exterior (Quiroga 1901: 236). Se encontraban en extremo norte del morro, cerca del camino que conduce a la Chilca. Por sus características arquitectónicas y emplazamiento hace pensar en construcciones incaicas. Areas de enterratorios fueron detectadas al oeste, norte y noreste de La Ventanita y al pie del Calvario, con sepulturas de forma circular, tapadas con grandes lajas (Bruch 1911).

Durante sus investigaciones, Kriskautzky (1999) dividió al asentamiento en siete sectores, identificando en los terrenos bajos cercanos al fondo de valle un conjunto constructivo asignado a la pre-

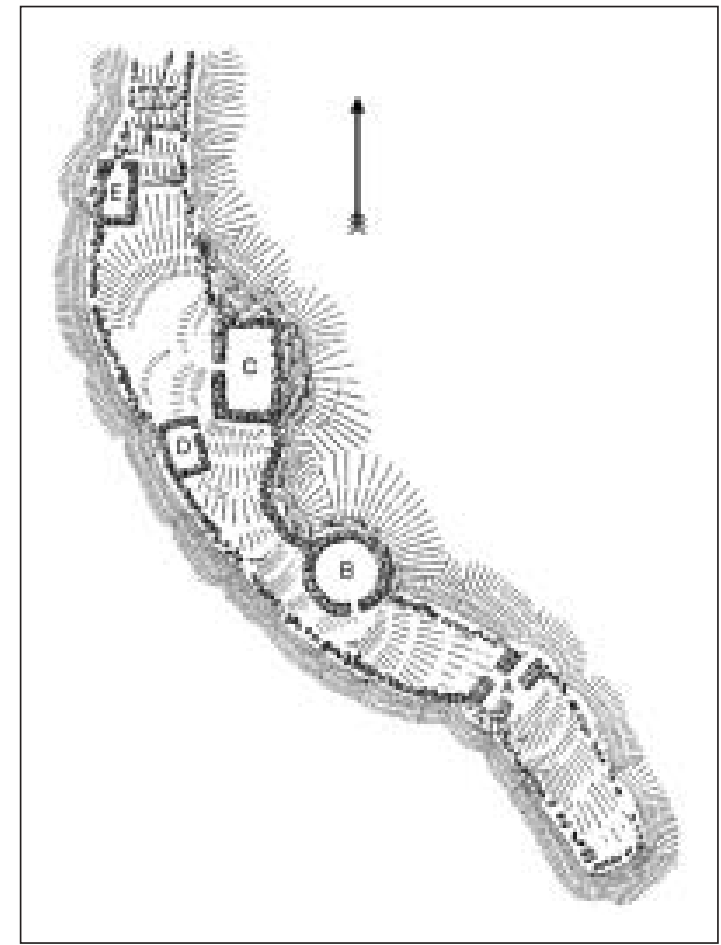

Figura 2. Cumbre de La Ventanita de Fuerte Quemado. Redibujado de Bruch (1911).

sencia incaica, denominándolo sector IV. La mampostería fue descrita como de piedras chatas pegadas con mortero de barro (Kriskautzky 1999: 128-129), en doble hilera horizontal sin relleno interior, con espesores de muros en torno a los 60 $\mathrm{cm}$, piso y revoque interno con ocre amarillento, conformando recintos con plantas del tipo cancha o "rectángulo perimetral compuesto" (RPC). Se informó sobre un fechado radiocarbónico de $680 \pm 70$ AP para este sector (Kriscautzky 1999: 181). La cerámica de todo el asentamiento se componía de tipos tardíos, en particular Santa María Bicolor, pero en proporciones variables. Los fragmentos incaicos locales, Negro sobre Rojo, dominaban en el sector IV, no siendo registrados tiestos Cuzco Policromo. También estaban ausentes los tipos Yocavil, Averías y Famabalasto Negro sobre Rojo, los que suelen ser interpretados en relación con la presencia de mitmaq santiagueños introducidos en el valle por el Imperio. No obstante, corresponde mencionar que la colección de origen funerario adquirida por Bruch durante sus trabajos en la zona indica que existieron tumbas entre cuyas ofrendas se encontraban aríbalos incaicos cusqueños y locales (Bruch 1911: Figs. $83,84,85)$, un plato con asa en ojal Inca Paya 
(Bruch 1911: Fig. 70), Yocavil Rojo sobre Blanco (Bruch 1911: Figs. 67, 68, 69) y Famabalasto Negro sobre Rojo (Bruch 1911: Figs. 58, 59), además de distintas vasijas Santamarianas y Loma Rica Bicolor, variedades cerámicas estas últimas congruentes con la problemática de una prolongada ocupación indígena en el área (Figuras 3 y 4b).

Se detectaron también obras de infraestructura relacionadas con tareas agrícolas, tales como extensos cuadros en la parte baja y canales de riego. En el piedemonte se presentaban, además, estructuras formadas por grandes patios o corrales comunicados con recintos elípticos, depósitos rectangulares y estructuras circulares con morteros. Es relevante consignar que en el denominado recinto C 44 del sector IV parece haber operado un taller de producción metalúrgica, centrado en un gran fogón al que se asociaban escorias con contenido de cobre y oro y restos de minerales fundentes (Kriskautzky 1999: 141-143).

\section{Las Mojarras}

Los vestigios arqueológicos más conocidos son los correspondientes al poblado alto denominado Cerro Pintado (Bruch 1911) y los materiales de enterratorios recuperados en sus inmediaciones por Weiser y Woters en 1923 (Baldini y Albeck 1983). Respecto de la información que suministró Bruch, nos interesa señalar que, en la cima del cerro, fue registrado "un pequeño grupo de construcciones angulares, cuadradas y de rectángulos alargados, dispuestas con cierta simetría”. Agregó luego:

"El grupo principal de estas construcciones representa un edificio compuesto de una gran pirca rectangular, que mide $40 \mathrm{~m}$ de largo por 12 de ancho y parece haber servido de patio; a éste se hallan adheridas las habitaciones (...) Una gran galería rectangular y sobresaliente forma dos martillos por su costado occidental; además, aún existen otros tres cuartuchos: uno perfectamente cuadrado, ubicado en la mitad de la pared norte, en parte hoy derrumbado; mientras que los otros dos, rectangulares, se hallan del lado opuesto (Bruch 1911: 104, fig. 101).

Hizo notar este autor que, en el interior de la gran "cuadra", existía un círculo de 3 m de diámetro, colocado a flor de tierra y formado por piedras laja (Figura 5).

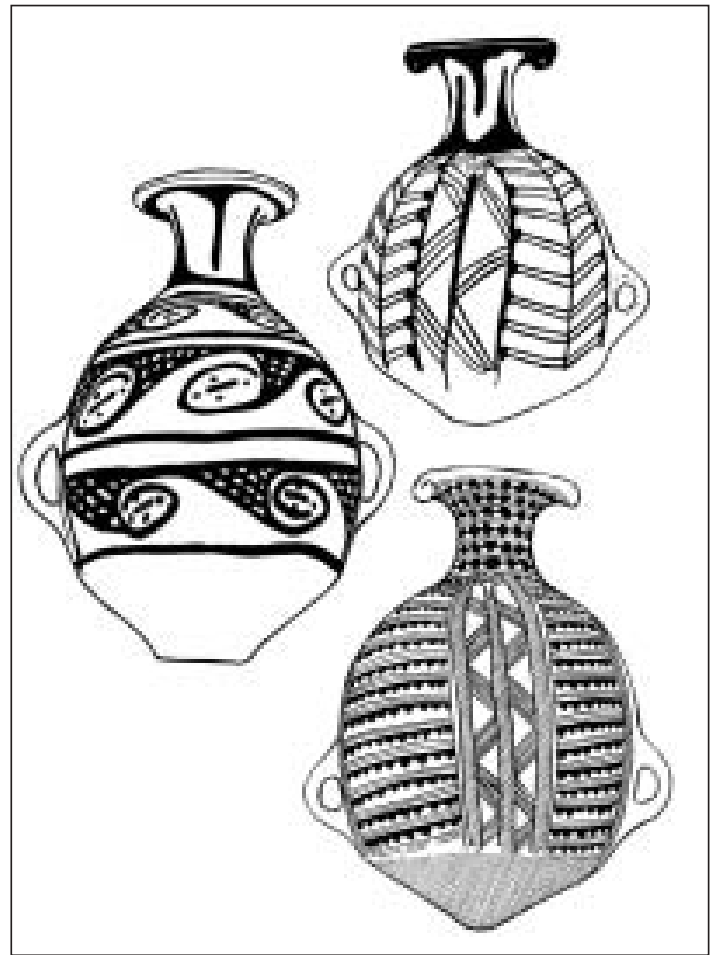

Figura 3. Aríbalos incaicos procedentes de Fuerte Quemado. Redibujado de Bruch (1911).

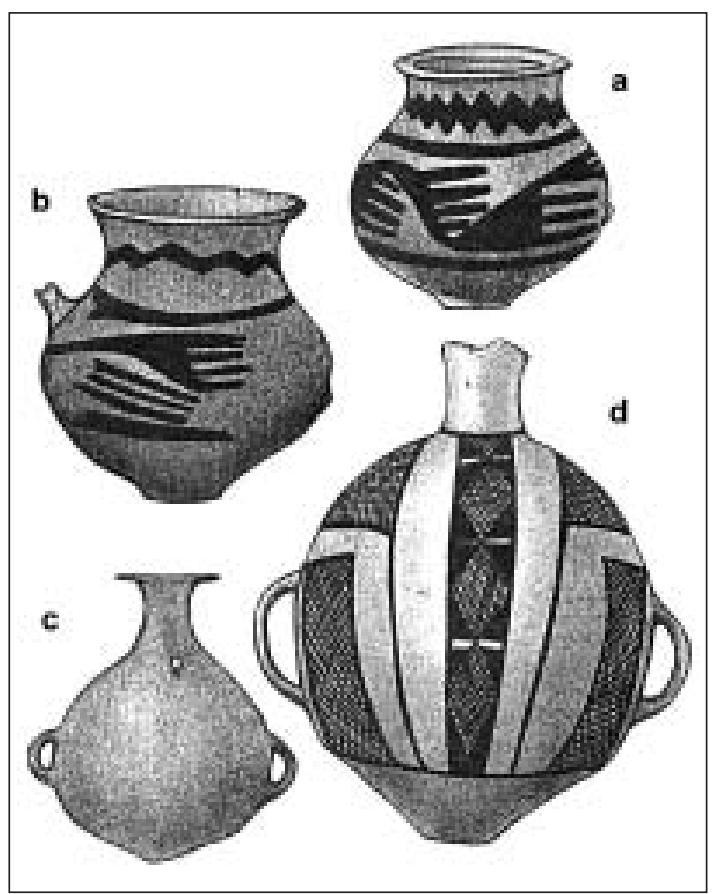

Figura 4. Alfarería ilustrada por Outes (1907): a y b) vasijas Famabalasto Negro sobre Rojo (procedentes de Santa María y Fuerte Quemado, respectivamente); c y d) aríbalos incaicos (procedentes de Pabellón y Santa María, respectivamente). 


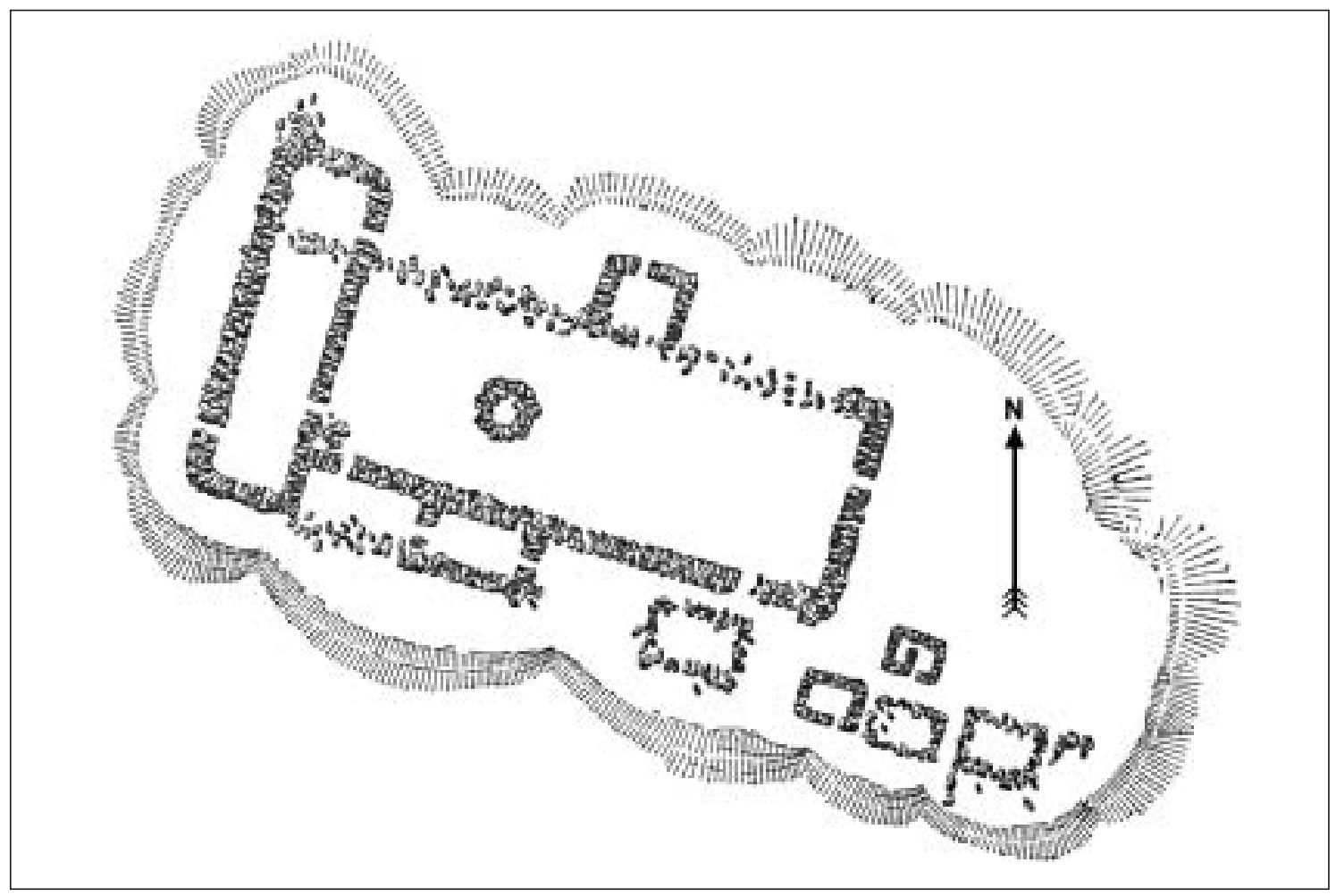

Figura 5. Construcciones en la cumbre del Cerro Pintado de Las Mojarras. Redibujado de Bruch (1911).

A unos $100 \mathrm{~m}$ de la gran cancha rectangular, Bruch (1911: Fig. 102), registró la presencia de un recinto de $4 \mathrm{~m}$ por $4.50 \mathrm{~m}$, de cuidada edificación y que conservaba aún el dintel de su puerta formado por dos largas piedras. En la fotografía publicada puede observarse el vano trapezoidal y el muro adornado con una hilera de bloques blancos a media altura. Además de sus características formales, el tipo de pircado, similar a los muros del R57 de la Quebrada del Puma, en Rincón Chico (véase más adelante), sugiere una remodelación durante la época incaica. Debe indicarse que la ladera oriental del cerro se encontraba cubierta por terrazas sostenidas por muros de contención, que servían de base a recintos alineados y hasta 1986, al menos, podía constatarse la modalidad arquitectónica de muros decorados con bloques de cuarzo formando líneas angulares, presente también en Rincón Chico (Tarragó 1987).

Durante nuestras investigaciones hemos registrado otras 10 áreas con construcciones de distinta complejidad al sur del cerro principal de Las Mojarras. La planta básica de estas construccio- nes es un gran recinto rectangular con estructuras más pequeñas, rectangulares o circulares, asociadas. Se realizaron excavaciones de salvataje en el sitio denominado LM-1, del cual sólo se conservaba un montículo de $30 \mathrm{~m}$ de largo por $20 \mathrm{~m}$ de ancho y que parece haber estado vinculado a construcciones pircadas que fueron demolidas por el propietario de los terrenos para dejar espacio para el cultivo. En superficie y en excavación fue recuperada una gran cantidad de fragmentos de cerámica de distintos tipos, incluyendo Santa María Bicolor y Tricolor, San Josél Shiquimil, Famabalasto Negro Grabado, Famabalasto Negro sobre Rojo e Inca Provincial (fragmentos de platos y aribaloides, ver Figura $6,12 \mathrm{a}$ y $12 \mathrm{~b}$ ). Las evidencias sugieren que el lugar, en el cual se obtuvo un fechado radiocarbónico sobre carbón vegetal (LP1310, ver Tabla 1), formó parte de un área de descarte de materiales, pero en la cual también se habilitaron y utilizaron con intensidad un fogón en cubeta para cocción de alimentos y una gran estructura de combustión de altas temperaturas de $2 \mathrm{~m}$ de diámetro, donde se ubicaron indicios pirometalúrgicos. $\mathrm{Al}$ respecto, corresponde men- 


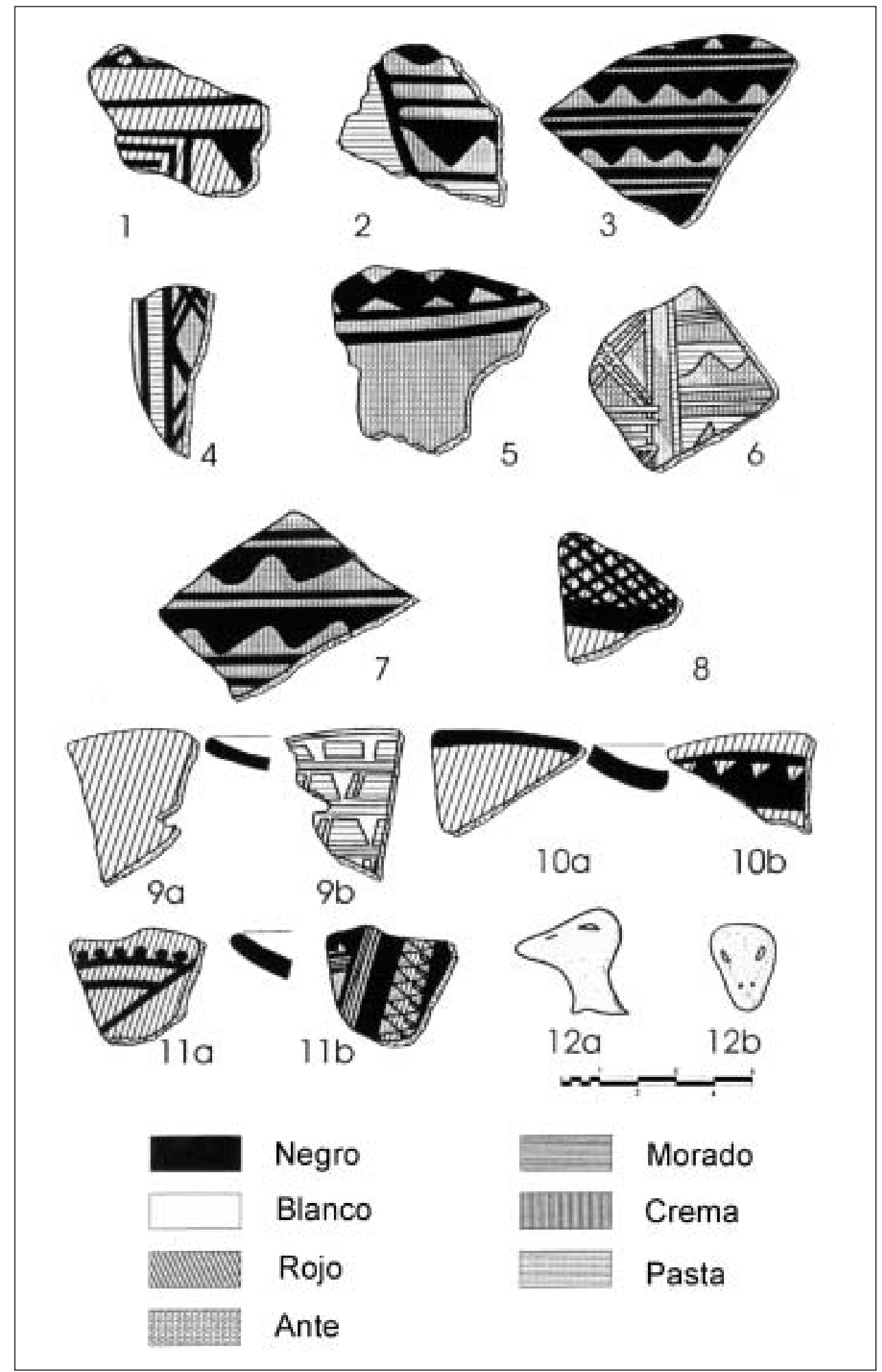

Figura 6. Fragmentos de alfarería incaica: 1) Ampajango II; 2 a 11) Punta de Balasto; 12) Las Mojarras LM-1. 


\begin{tabular}{|llccc|}
\hline Procedencia & Muestra $^{\mathbf{0}}$ & Edad C14 AP & Años DC Cal. 1 Sg & Años DC Cal. 2 Sg \\
\hline R. Chico 1-302 & Beta 131673 & $560 \pm 60$ & $1310-1425$ & $1295-1445$ \\
R. Chico 13 & Beta 131674 & $560 \pm 50$ & $1315-1420$ & $1400-1435$ \\
R. Chico 14 & LP 1015 & $430 \pm 60$ & $1433-1610$ & $1407-1637$ \\
R. Chico 12 & Beta 130222 & $490 \pm 50$ & $1410-1445$ & $1395-1470$ \\
P. de Balasto & LP 816 & $680 \pm 60$ & $1291-1402$ & $1273-1430$ \\
Ampajango II & Beta 146374 & $340 \pm 130$ & $1430-1660$ & $1320-1950$ \\
Loma Rica & LP 983 & $380 \pm 60$ & $1446-1634$ & $1430-1653$ \\
LM-1 & LP 1310 & $400 \pm 60$ & $1441-1627$ & $1419-1648$ \\
R. Chico 1-ML25 & Beta 162379 & $630 \pm 40$ & $1295-1399$ & $1286-1413$ \\
R. Chico 1-ML39 & Beta 162380 & $400 \pm 20$ & $1445-1491$ & $1439-1619$ \\
R. Chico 1-139 & LP 1390 & $310 \pm 60$ & $1491-1656$ & $1443-1954$ \\
R. Chico 1-111 & LP 1426 & $490 \pm 70$ & $1430-1660$ & $1309-1621$ \\
\hline
\end{tabular}

Tabla 1. Fechados radiocarbónicos referidos en el texto.

cionar que fueron registrados grandes nódulos de escorias de combustión (L. González 2001), refractarios fracturados, restos de minerales de cobre y un pequeño fragmento de bronce estañífero.

\section{Rincón Chico}

La localidad arqueológica de Rincón Chico se ubica a unos $5 \mathrm{~km}$ de la ciudad de Santa María, abarcando un área aproximada de 500 ha. Los vestigios de construcciones prehispánicas, identificados como 35 sitios, se despliegan por distintos espacios topográficos. El sitio 1, en el que se contabilizan más de 360 construcciones dentro de un área de unas 40 ha, se emplaza en la cima y ladera oriental de un espolón que se desprende de la sierra del Cajón. Los restantes sitios se distribuyen hacia el este, en el amplio cono de deyección de la sierra, llegando hasta la llanura aluvial adyacente al margen izquierdo del río Santa María. Consisten, en general, en conjuntos arquitectónicos compuestos por grandes canchones rectangulares a los que se adosan estructuras más pequeñas, rectangulares y circulares, en número que puede ir de uno a ocho (Tarragó 1987, 1995, 1998). Los materiales recuperados en las excavaciones realizadas en distintos sitios y los resultados de 28 fechados radiocarbónicos indican una prolongada ocupación entre el siglo IX y la dominación colonial.

Las evidencias incaicas en Rincón Chico son sutiles y limitadas a algunos sectores de la localidad. El poblado central cuenta con un espectacular escenario ceremonial en una quebrada que une el piedemonte del cerro con las construcciones en la cima. El lugar es conocido, tradicionalmente, con sugestivos nombres (Abra del Sol, Quebrada del Puma) y constituye un paisaje "culturizado" a partir de construcciones que cortan la pendiente a diferentes niveles (Tarragó y González 2000 Ms). Junto a una torrentera de bloques pegmatíticos rosados visible desde larga distancia (Figura 7) se dispusieron plataformas con muros de piedra oscura en los que se imbrican bloques de cuarzo blanco formando dibujos abstractos y figurativos. Entre estas construcciones se destaca la denominada "Plataforma Tricolor" con un muro de más de $2 \mathrm{~m}$ de altura y que, a diferencia de los otros, combina bloques rosados, blancos y negros (Figura 8). En dos de las estructuras del sector (302 y 111) se obtuvieron fechados radiocarbónicos (Beta 131673 y LP 1424) y han sido establecidas alineaciones astronómicas que sugieren celebraciones calendáricas (Reynoso $2001 \mathrm{Ms)}$ ). La cumbre del cerro, con su acceso restringido y las cualidades que presentan algunas de sus construcciones, parece haber constituido un área diferenciada, en lo social y lo simbólico, del resto del poblado y reservada para la élite político-religiosa (Tarragó 1987; Tarragó y González 2000 Ms). El espacio ceremonial habría ganado magnitud a lo largo de los siglos, siendo resignificado durante la ocupación incaica. En el proceso, no sólo las cualidades de las prácticas rituales habrían sido adecuadas a la cosmología estatal, sino que también se llevaron a cabo remodelaciones arquitectónicas en puntos estratégicos del paisaje. Por ejemplo, en el denominado recinto $\mathrm{n}^{\circ} 57$, que cierra el Abra del Sol en el camino ascendente del bajo hacia la cumbre, se advierten paredes de pirca canteada, una rampa y ángulos interiores bien re- 


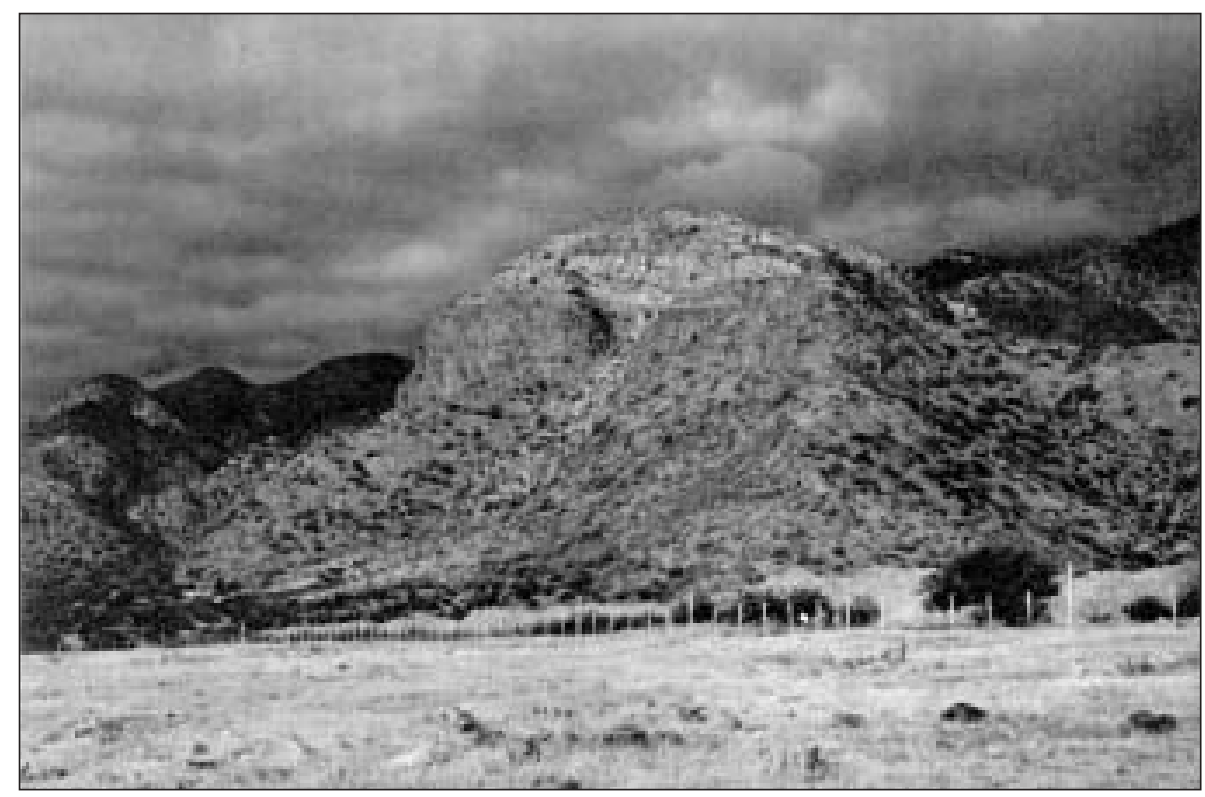

Figura 7. Cerro de Rincón Chico. En el centro, la Torrentera Rosada.

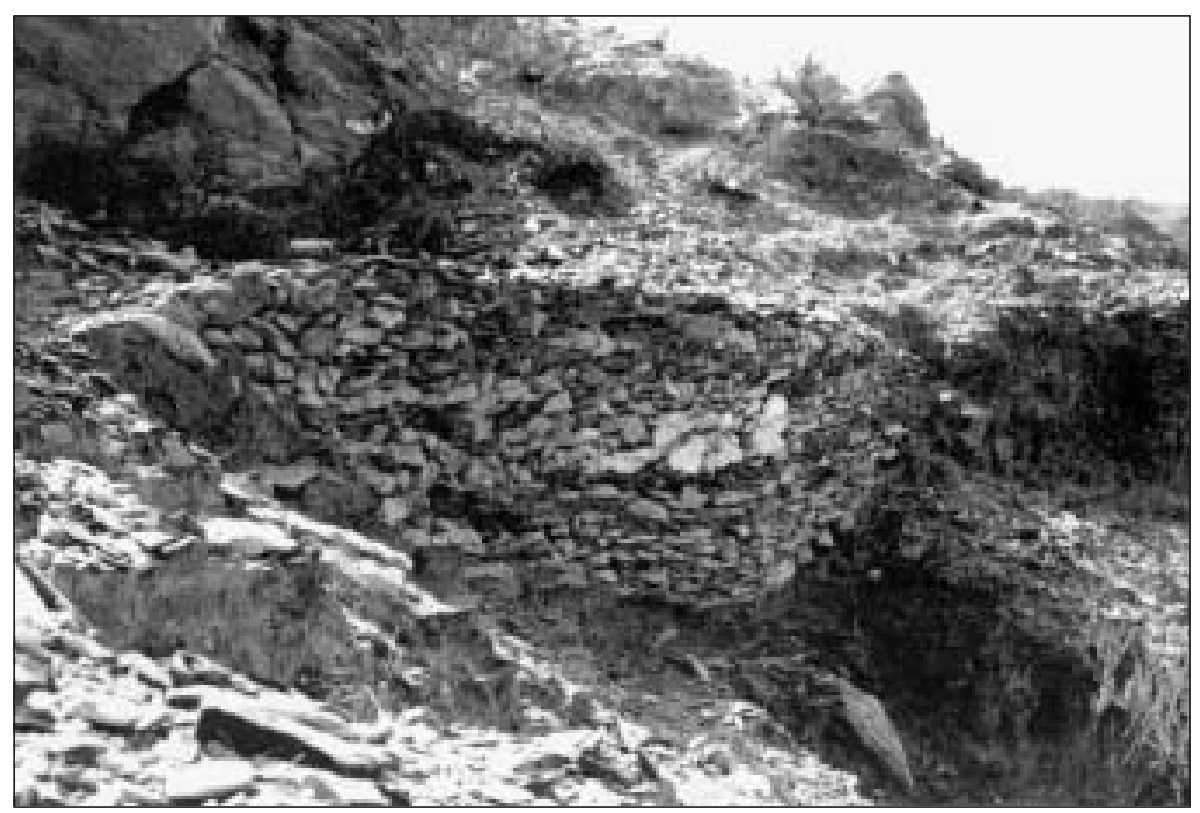

Figura 8. Muro externo de la plataforma tricolor en la Quebrada del Puma de Rincón Chico.

sueltos, modalidades distintas a las empleadas en las construcciones de tradición local y que guardan similitudes con los registros de La Ventanita, en Fuerte Quemado y los del edificio de la cumbre del Cerro Pintado.
Por otro lado, la entrada de la quebrada se encuentra cercada por un abanico de grandes peñascos rodeados por plataformas semicirculares en los cuales parecen haber tenido lugar rituales que incluían sacrificios de seres humanos y de animales (Tarragó y González 2000 Ms). Estructuras similares se encuentran a unos cientos de metros 
al sur, en el denominado Sector XIII. En este lugar, las evidencias de prácticas ceremoniales son más claras, habiéndose registrado piedras pulidas y clavadas en el terreno, fogones de incineración de ofrendas, restos humanos de infantes y adultos y un fragmento de una gran campana oval de bronce (González y Doro 2003; González y Cabanillas 2004). En dos de estas estructuras (ML 25 y ML 39) fueron obtenidos fechados radiocarbónicos (Beta 162379 y 162380). Todo apunta a indicar que en el caso de estas huancas la ocupación incaica no implicó modificaciones en las prácticas ceremoniales de tradición local (Figura 9).

Ya en los sectores correspondientes al cono de deyección que desciende desde la sierra, el sitio 4 ofreció una muestra cerámica de superficie en la que predominaba el grupo Santa María Bicolor, pero que incluía un pie de compotera tardío, Inca o Hispano-indígena. Un fragmento similar fue registrado en el sitio 5. El sitio 10, anexo al sector VIII del poblado central, presenta algunos detalles constructivos que sugieren la intervención imperial (Figura 10) y, en superficie, fue recuperado un fragmento de cerámica Inca Provincial (Tarragó 1998). En las cistas funerarias del sitio 21 investigadas por Mendonça y colaboradores (2003), los hallazgos apuntan a indicar una larga reutilización de las estructuras, hasta momentos de contacto con los europeos. Sugestivamente, los materiales correspondientes a los momentos incaicos son inexistentes o difíciles de diferenciar de la Conquista, pues en los entierros más recientes aparecen algunas ollitas con pedestal de factura local y puntas de proyectil confeccionadas en hueso, del tipo "cola de golodrina" que se dan tanto en Inca local como en la época de las Guerras Calchaquíes contra el español.

La presencia cusqueña se hace mucho más evidente en los sitios ubicados en la franja más cercana al fondo del valle. El sitio 12, en el cual se obtuvo un fechado del piso de ocupación, fue definido como una variante de cancha, y entre los más de 2000 fragmentos de alfarería recuperados, en superficie y excavación, algunos corresponden al tipo Inca Provincial (L. González et al. 2001). En el sitio 13, el 5\% de los fragmentos de alfarería de superficie fue identificada como Inca Provincial, destacándose fragmentos de platos "pato" y aribaloides (Tarragó et al. 2002). En el sitio 14 fue fechada un área de elaboración de bebidas a gran escala, con alfarería de tipos incaicos (Tarragó et al. 1999).

El sitio 15, el más intensamente estudiado de la localidad, con más de $500 \mathrm{~m}^{2}$ de excavación y 12 fechados radiocarbónicos que se escalonan entre los siglos IX y XVII, proporcionó interesante información acerca de la presencia incaica en el lugar. En la instalación funcionó un taller metalúrgico cuyas actividades, iniciadas desde los comienzos mismos de la ocupación, fueron ganando en intensidad y sofisticación a lo largo de los siglos, utilizando un sistema de fundición basado en crisoles calentados en fogones. Los artesanos, además de desarrollar originales innovaciones técnicas, produjeron aleaciones de bronce utilizando estaño, cuyos depósitos más cercanos se ubicaban en un rango de 150 a $170 \mathrm{~km}$ al sureste. La ocupación incaica en el taller se reflejó en un dramático incremento de las actividades metalúrgicas, con la erección de una batería de hornos del tipo huayra en un sector aledaño y la manufactura de lingotes (Figura 11). Sin embargo, continuaron vigentes los procedimientos tecnológicos desarrollados localmente y las áreas de trabajo existentes fueron incorporadas a una organización productiva que incluía la fundición de minerales, la refinación de metales base y la preparación de aleaciones (L. González 2001, 2002). No fue abandonada la manufactura de los objetos del repertorio regional con alto peso simbólico, como los discos y las campanas ovales y cabe mencionar que entre los miles de fragmentos de alfarería recuperados en recolecciones de superficie y en excavación no fue identificado ninguno correspondiente a tipos incaicos ni a las modalidades Yocavil o Famabalasto Negro sobre Rojo.

\section{Medanitos-Famatanca}

Este asentamiento se ubica a $5 \mathrm{~km}$ al sur de Rincón Chico, en el comienzo de un antiguo camino que, a través de la Quebrada de Agua del Sapo, comunica con el valle del Cajón (Nastri 1998: 262). El sector Medanitos, relevado expeditivamente por nosotros, consiste en casi medio centenar de estructuras alineadas de norte a sur, cubriendo un área mínima de 2 ha y en malas condiciones de conservación. Se identificaron conjuntos que asociaban hasta media docena de recintos rectangulares de distintas dimensiones, con carac- 


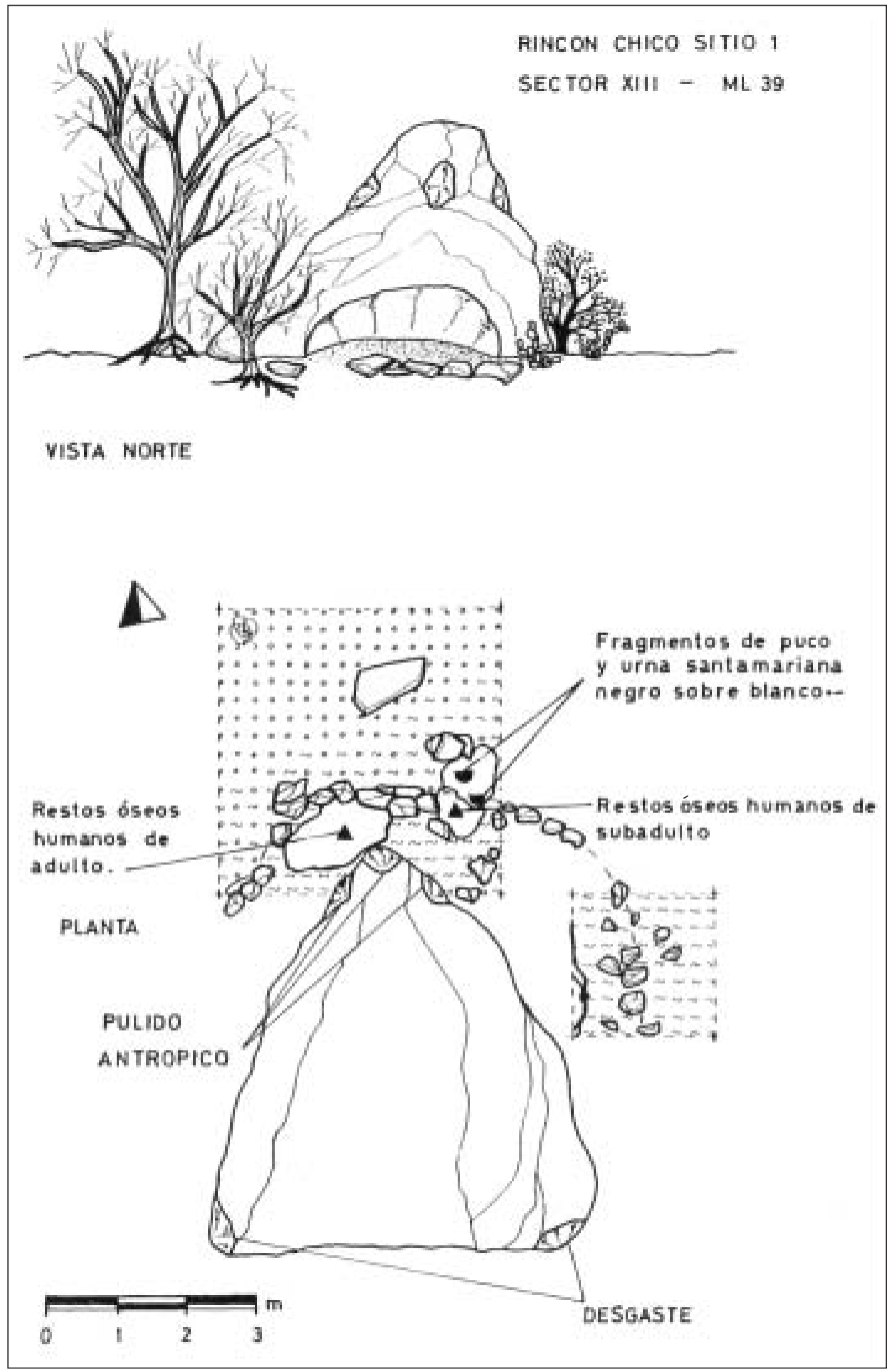

Figura 9. Rincón Chico, Sector XIII. Huanca ML39. 
VIENTOS DEL SUR. EL VALLE DE YOCAVIL...

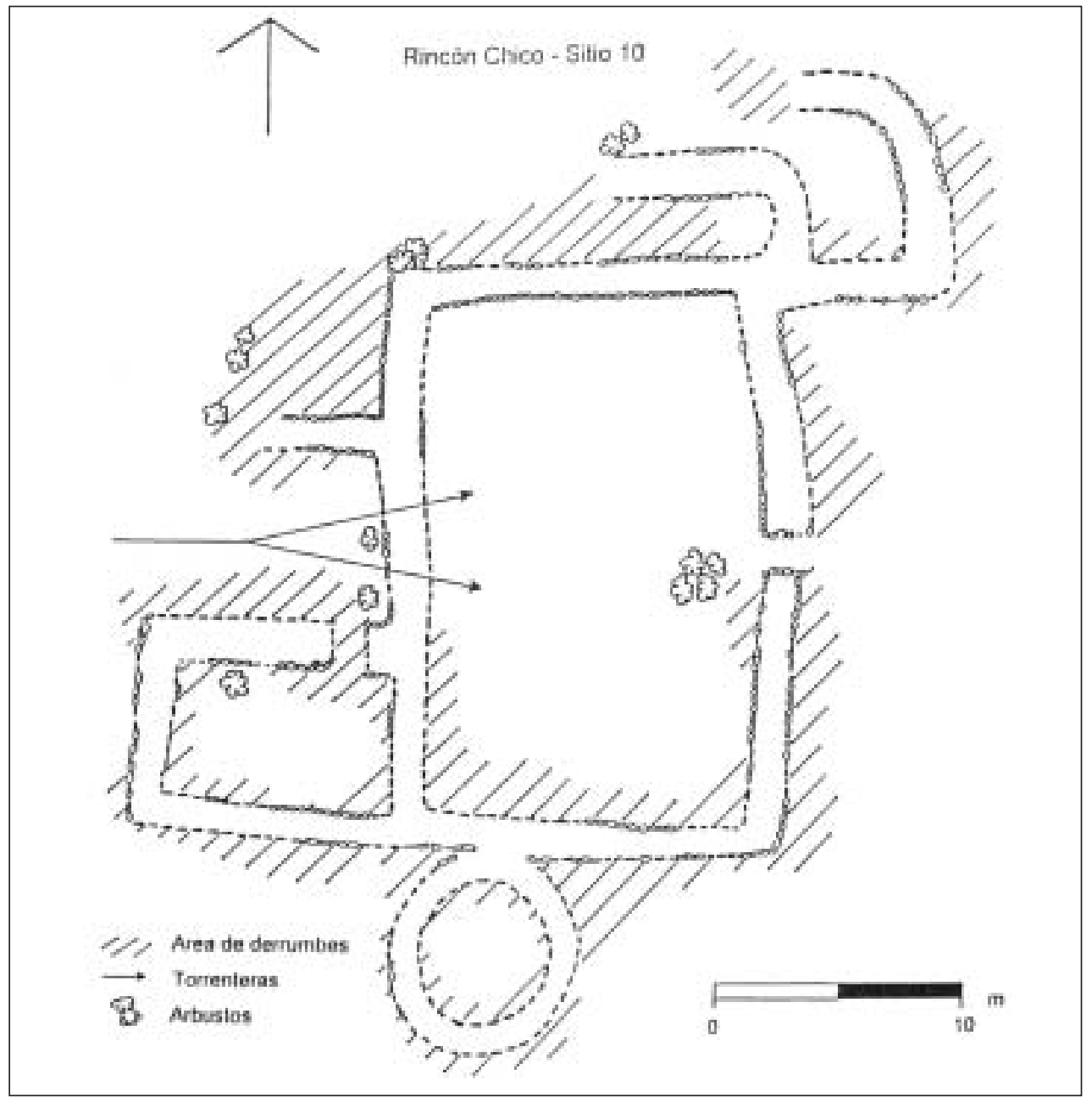

Figura 10. Planta de Rincón Chico 10.

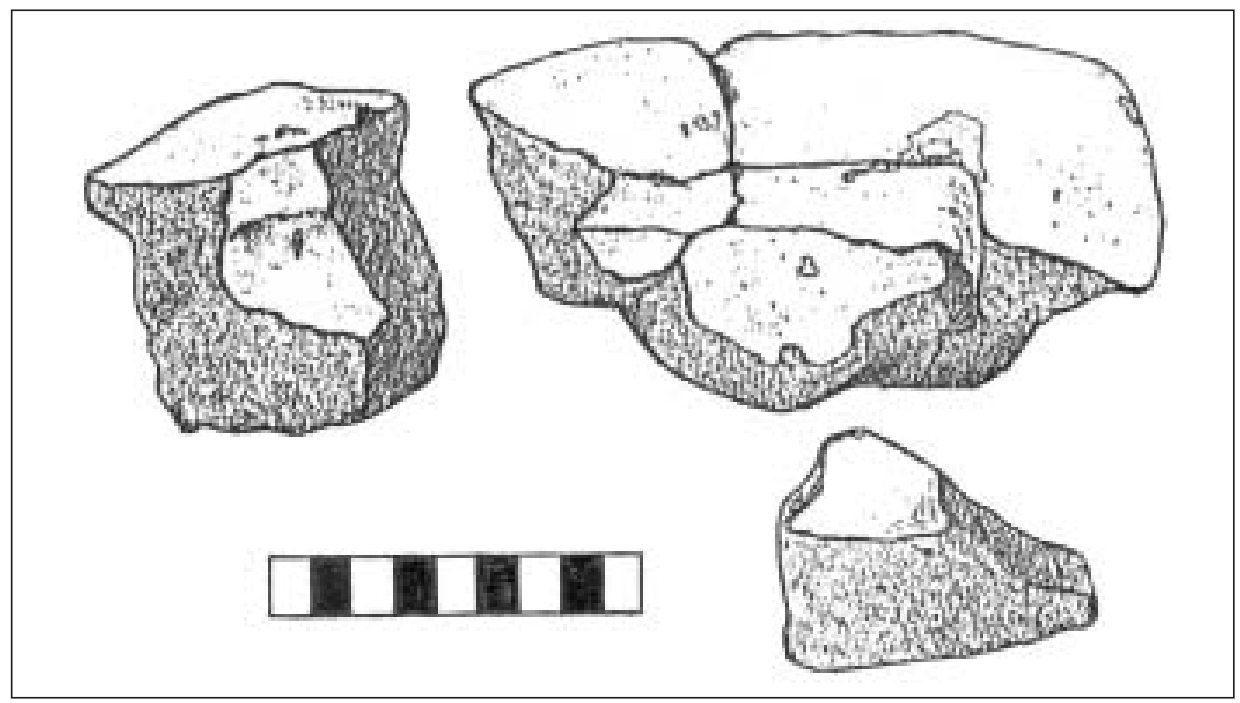

Figura 11. Rincón Chico 15. Molde de lingote. 
terísticas arquitectónicas que permiten postular influencias incaicas. De igual modo, en la muestra cerámica de superficie fueron reconocidos algunos fragmentos del tipo Inca Provincial.

\section{Cerro Mendocino}

El poblado alto de Cerro Mendocino, conocido desde fines del siglo XIX, se ubica sobre una escabrosa cumbre de las estribaciones meridionales de la sierra del Cajón, a más de $400 \mathrm{~m}$ sobre el nivel del valle. Por su difícil acceso y la presencia de construcciones defensivas, se suele considerar al asentamiento una "fortaleza". El primer plano de la distribución de las estructuras fue realizado por Bruch (1911), siendo luego mejorado por Weiser (1920 Ms), ocasión en la cual se graficaron 101 estructuras pircadas, además de líneas de muros de contención o "murallas". Las únicas excavaciones en recintos fueron realizadas hace más de cuatro décadas y estuvieron a cargo de un equipo dirigido por Cigliano (Carrara et al. 1960). Durante estos trabajos fueron registradas en el área de la cumbre siete líneas de gruesas murallas de $1.50 \mathrm{~m}$ de altura, construidas con lajas superpuestas, sin argamasa. Hacia el noroeste del cerro, la muralla inferior enlazaba con dos recintos circulares a los que se denominó "troneras" (Carrara et al. 1960: Fig. 10 y Lám. IV). En otras construcciones que se asomaban sobre las quebradas de los lados del cerro, se encontraron depósitos de rodados pequeños y de tamaño uniforme, los cuales habrían sido llevados desde el río Santa María para ser utilizados como proyectiles (Carrara et al. 1960: 30-31).

Los muros de las habitaciones eran dobles, con relleno interior de ripio y alcanzaban un ancho que podía superar el metro. Los recintos de planta rectangular, a veces asociados e intercomunicados, resultaron ser los más numerosos, siendo mucho menos frecuentes los de planta circular. Se efectuaron excavaciones en dos de las construcciones rectangulares. En una de ellas, sobre el piso de ocupación se hallaron evidencias de una techumbre de ramas y paja incendiada. Los investigadores concluyeron que el asentamiento alto correspondió a un "pueblo fortificado de ocupación permanente" de "carácter santamariano" preincaico (Carrara et al. 1960: 36). Un fechado obtenido de los restos de postes del techo dio $1300 \pm 60$ AP, fecha considerada demasiado temprana por
Cigliano (1966: 9), pero que sería oportuno revaluar considerando los factores de envejecimiento de la muestra y la posibilidad de un inicio más temprano de la ocupación en lugares o morros elevados.

En la oportunidad también se efectuaron excavaciones en estructuras emplazadas sobre la ladera oriental. El denominado Núcleo A constaba de cuatro recintos realizados en pirca simple de lajas, con un ancho de paredes de $0.60 \mathrm{~m}$ y que en algunos lugares alcanzaban casi $2 \mathrm{~m}$ de altura (Figura 12). La excavación efectuada sólo permitió recuperar espículas de carbón y fragmentos de alfarería tosca (Carrara et al. 1960: 39). El Núcleo B lo integraban recintos construidos sobre el cono de deyección. Se excavó uno "de forma subrectangular con ángulos redondeados" y otro circular, no determinándose en ninguno de ellos el piso de ocupación ni efectuándose hallazgos de material cultural (Carrara et al. 1960: 3940). Por último, se excavó un recinto en el Núcleo C, ubicado "al N.O. del Núcleo A", detectándose los restos carbonizados de un techo y recuperándose de fragmentos de alfarería de los tipos San José y Santa María Tricolor. Este recinto contaba con paredes de piedra lajas y rodados, en pirca doble de $1 \mathrm{~m}$ de ancho (Carrara et al. 1960: 40-41). La muestra que corresponde a esta habitación arrojó un valor de 610 $\$ 85$ AP (Cigliano 1966: 9).

Nuestras prospecciones en la zona posibilitaron ubicar una construcción en la quebrada de acceso oriental a la cumbre del Cerro Mendocino, la cual, probablemente, corresponda a la descrita anteriormente como Núcleo A. De acuerdo a sus características constructivas, que se diferencian de modo notable con las observables en las estructuras de raíz local, puede postularse que dicha construcción se vincula con la ocupación incaica en la zona. Asimismo, a pocos centenares de metros hacia el este, en la boca de la misma quebrada, registramos una gran plaza de planta trapezoidal que cubre unos $4000 \mathrm{~m}^{2}$ y que no había sido detectada con anterioridad. La construcción, emplazada sobre una angosta terraza delimitada por profundas torrenteras estacionales, presentaba muros dobles de piedra sin relleno, en los que se combinaban grandes bloques sin trabajar junto con otros con canteado expeditivo. Dentro de la plaza se verificaron líneas de muros muy borradas que 


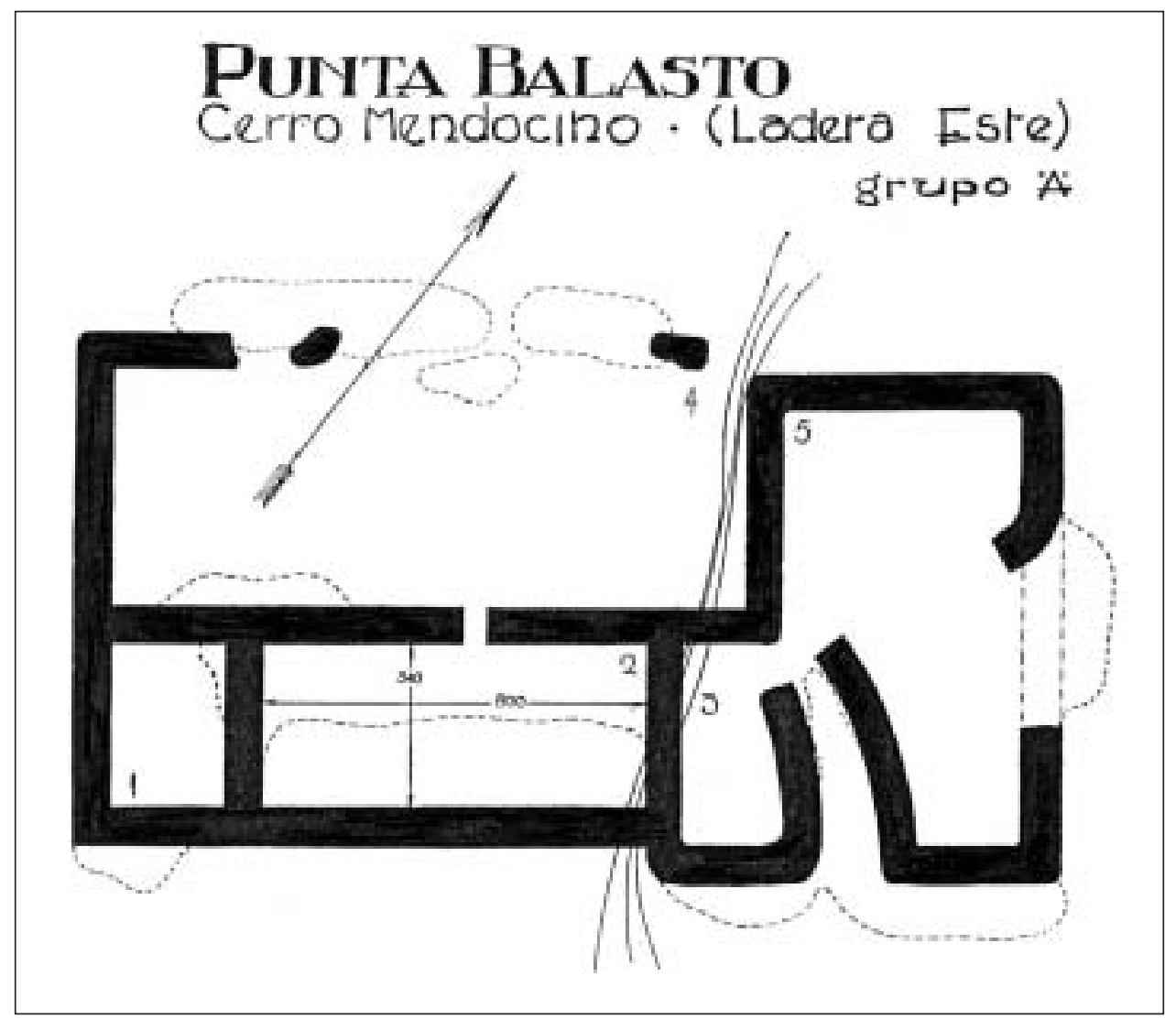

Figura 12. Construcciones del Núcleo A de Cerro Mendocino. Tomado de Carrara y colaboradores (1960: 37).

sugieren subdivisiones internas. Junto a los muros exteriores se presentaban recintos circulares interpretados como depósitos y en el lado norte se ubicó un acceso dotado de una elaborada rampa. Los fragmentos cerámicos recuperados en superficie fueron escasos, pero entre ellos se identificaron tipos Famabalasto Negro sobre Rojo e Inca Provincial (L. González 1999).

\section{Fundición Navarro}

A poco menos de $1 \mathrm{~km}$ al sur del Cerro Mendocino se localiza Fundición Navarro, un sitio de procesamiento pirometalúrgico de épocas coloniales tempranas, pero fundado sobre una previa ocupación indígena (L. González 2000). El lugar incluye una cancha pavimentada con lajas para el depósito y la trituración de minerales de cobre, una estructura monticular formada por la acumulación de escorias de fundición, un grupo de cuatro recintos pircados y un canal recubierto con lajas, de cerca de $1 \mathrm{~km}$ de longitud, que captaba las aguas del río Santa María y las llevaba hasta la cancha. La cerámica presente en superficie era escasa y de tipo utilitario. La técnica constructiva empleada en el canal es similar a la verificada en algunas de las construcciones del tambo de Punta de Balasto, que se levanta en las cercanías, del otro lado del río (ver más adelante).

\section{Bicho Muerto}

El asentamiento de Bicho Muerto ocupa las laderas bajas y el piedemonte del Morro Blanco, la máxima altura del extremo meridional de la Sierra del Cajón. En un espacio de aproximadamente 180 ha fueron identificados tres grupos principales de construcciones (L. González 1995: 102). Bicho Muerto Fortaleza, con 35 recintos circulares, rectangulares y trapezoidales, cubre poco más de 1 ha en un circo natural que se abre hacia el sur y que está cerrado con una muralla continua de pirca doble sin relleno, que alcanza una longitud de $218 \mathrm{~m}$ y cuenta con un único acceso en su 
parte central. Bicho Muerto Ranchos, con 50 recintos de cuidadosa construcción en un espacio de 7 ha, se encuentra a una cota $50 \mathrm{~m}$ más baja que el anterior grupo. En las construcciones predomina la planta de tendencia rectangular, en ocasiones asociadas a recintos circulares. Por último, Bicho Muerto Bajo se distribuye en el amplio espacio del cono de deyección de la sierra, hasta la línea de bosque relictual que corre a lo largo del río Santa María. En los sectores protegidos son visibles conjuntos de hasta siete recintos rectangulares y circulares asociados. Fue detectada un área de enterratorios y también un tramo de camino de $8.30 \mathrm{~m}$ de ancho, con laterales pircados, que pudo reconocerse a lo largo de $340 \mathrm{~m}$. Estos últimos rasgos fueron registrados por la expedición realizada por Weiser (1920 Ms) en la zona y aparecen señalados en el plano que se produjo en esa ocasión.

La muestra cerámica de superficie era escasa y correspondía a tipos tardíos. En las adyacencias del acceso al sector Fortaleza, dentro de una estructura circular de $9 \mathrm{~m}$ de diámetro, fueron recuperados algunos fragmentos Inca Provincial y Famabalasto Negro sobre Rojo. La presencia imperial está sugerida, además, por el tramo de camino que atraviesa el cono de deyección con rumbo a la entrada de la quebrada del Mendocino, frente a la cual se encuentra el tambo de Punta de Balasto, así como por los detalles constructivos observables en algunas estructuras, sobre todo en el sector Ranchos.

\section{El Trapiche}

Lindante con el sector Bajo de Bicho Muerto, en el borde del bosque de algarrobo y chañar y a menos de $30 \mathrm{~m}$ de una estructura del tipo cancha, se encuentra El Trapiche, una instalación metalúrgica colonial en algunos aspectos parecidos a Fundición Navarro. En este caso fue registrada una docena de construcciones rectangulares de pirca doble sin relleno y escalerados que compensan el declive natural. De una de estas construcciones el propietario de los terrenos extrajo dos grandes piedras circulares de molienda de minerales. Otra de las estructuras contiene los restos de un horno de cuba, derrumbado y con su fondo excavado, presumiblemente para recuperar el metal que se habría filtrado a través de la solera. Los análisis de los restos de minerales de cobre recuperados mostraron que las menas eran similares a las que fueron procesadas en Fundición Navarro. Teniendo en cuenta la información geológica del área y las noticias sobre laboreos en épocas históricas, fue propuesto que en ambos casos se benefició un yacimiento ubicado en la serranía inmediata (L. González 2000: 39-40). La tecnología empleada en El Trapiche no deja lugar a dudas que se trata de una ocupación colonial temprana. Pero la vecindad de las construcciones de Bicho Muerto dio lugar para proponer la hipótesis que los europeos reocuparon y transformaron una planta metalúrgica fundada en épocas incaicas.

\section{Punta de Balasto}

Este tambo se ubica a $35 \mathrm{~km}$ al sur de Santa María y sus vestigios arquitectónicos abarcan 10 ha en el fondo del valle, entre la playa del río Santa María y la ruta 40. Las primeras informaciones fueron proporcionadas por Bruch, quien sugirió vinculaciones entre el tambo y el ya mencionado poblado alto de Cerro Mendocino, $3 \mathrm{~km}$ al norte (Bruch 1911: 127-128). El carácter incaico de Punta de Balasto y el local de la fortaleza fueron aclarados en los trabajos realizados medio siglo más tarde (Carrara et al. 1960: 16). En 1988, nuestro equipo comenzó registros planimétricos en el área y en 1996 fueron encaradas excavaciones exploratorias.

El terreno, con sedimento suelto, cruzado por torrenteras estacionales y azotado por los vientos, hace que gran parte de las construcciones aparezcan sepultadas por la arena. En nuestros relevamientos registramos 13 grupos de estructuras arquitectónicas, con varias cancha (Figura 13), un conjunto de nueve círculos de $3 \mathrm{~m}$ de diámetro (tal vez hayan existido dos más, actualmente borrados; Bruch 1911: 125-136; Carrara et al. 1960: 18-19), un tramo de camino de $3.70 \mathrm{~m}$ de ancho que cruza en forma recta al tambo, un ushnu rectangular con dos líneas de escalones, un grupo de media docena de depósitos rectangulares junto al camino, una kallanka de $400 \mathrm{~m}^{2}$ de superficie y una gran plaza poligonal (L. González 1999: 231).

Los muros de todas las construcciones fueron levantados con pirca doble sin relleno y con el uso de un sólido mortero arcilloso, pero se observaron variantes en cuanto a las características de las piedras utilizadas. En las estructuras al oriente del 


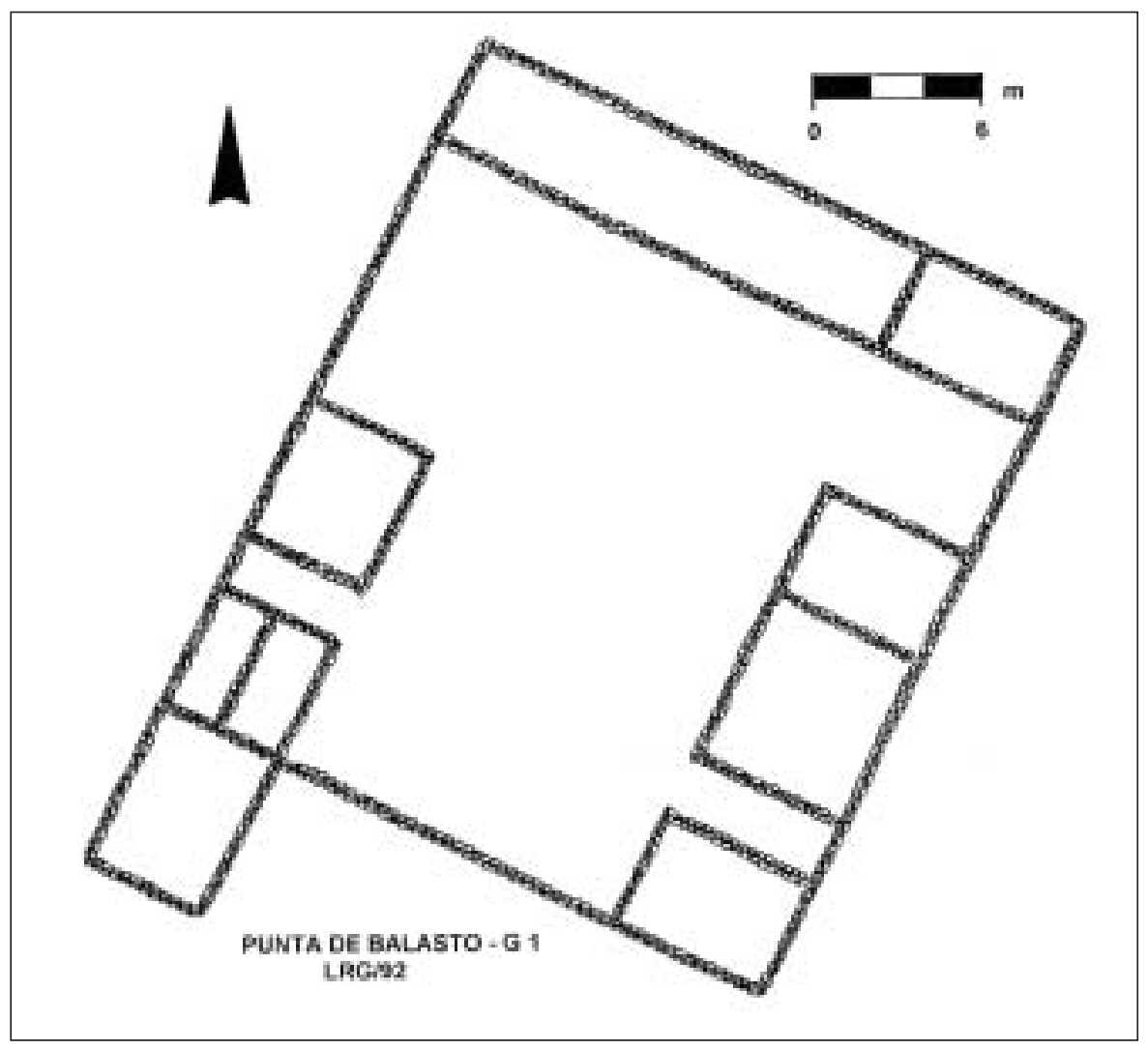

Figura 13. Punta de Balasto. Cancha en el Grupo 1 de estructuras.

camino se privilegiaron bloques rodados de granito, gneiss y andesita, seleccionados por sus volúmenes regulares y obtenidos en los cauces cercanos. En las construcciones occidentales, en cambio, se dispusieron preferentemente bloques canteados de cuarcita y pórfido que fueron extraídos de la Sierra del Cajón, a 1 km de distancia del otro lado del río, en las cercanías de Fundición Navarro.

Los fragmentos de alfarería recuperados en nuestros trabajos fueron abundantes y las proporciones por tipo coincidieron con las informadas a partir de anteriores intervenciones (Carrara et al. 1960). Alrededor del 30\% corresponden a Inca Provincial, identificándose formas de platos "pato", aribaloides y ollas con asa lateral (Figura 6, 2 a 11). Un $3 \%$ de fragmentos son de tipo Famabalasto Negro sobre Rojo y un 2\% Santa María Bicolor. El primer fechado radiocarbónico obtenido en una excavación exploratoria realizada en un sector de basurero al exterior de una cancha, arrojó un valor relativamente temprano (LP816). Cabe consig- nar que en superficie fueron registradas concentraciones de mineral de cobre del tamaño de grava fina. Por comparación con muestras patrón, se estableció que parte de este mineral habría sido extraído de depósitos de Capillitas-Cerro Atajo, distantes unos $40 \mathrm{~km}$ al sur, mientras que otros fragmentos guardan similitudes con las muestras analizadas procedentes de El Trapiche y de Fundición Navarro (L. González 2000).

Pajanguillo

A $2160 \mathrm{~m} . \mathrm{snm}$, a la vera de una antigua senda que conduce a Estancia Vieja, al este de Punta de Balasto, fue registrada una cancha de planta subrectangular, de $25 \mathrm{~m}$ por $25 \mathrm{~m}$ en sus dimensiones máximas (L. González 1999: 232). Fue construida con muros dobles sin relleno, utilizándose grandes bloques metamórficos sin trabajar o con un canteado grosero, lajas clavadas en las esquinas e incorporando, incluso, tres voluminosos bloques in situ. Al interior se verificaron subdivisiones rectangulares y circulares. Los es- 
casos fragmentos cerámicos en superficie se limitaban a tipos utilitarios muy deteriorados. Un centenar de metros al sur, sobre una loma alargada, pudo seguirse a lo largo de $300 \mathrm{~m}$ un tramo de camino de $2 \mathrm{~m}$ de ancho mínimo, en algunos sectores con un murete de contención en el lado de la pendiente. Hacia el fondo de valle, este camino se borra en los aluviones del río Pajanguillo pero, por su orientación, puede proponerse que se dirigía hacia el tambo de Punta de Balasto, distante 4 $\mathrm{km}$ en línea recta. En la dirección contraria, el camino se une con un sendero que, ingresando por la quebrada del río, conduce al tambo de Becobel, a 3600 m.snm, y, más arriba, hasta el asentamiento de Nevados del Aconquija (Hyslop y Schobinger 1991). En el área de Pajanguillo se encuentran ruinas de poblados preincaicos, de épocas formativas y tardías (Tarragó y Scattolin 1999). Cerca de $1 \mathrm{~km}$ al oriente, en Estancia Vieja, en la boca de la quebrada que trepa hacia las cumbres del Aconquija, hemos ubicado estructuras de piedra muy deterioradas $y$, entre los fragmentos de alfarería de superficie, identificamos algunos asignables a tipos incaicos.

\section{Ampajango II-Rosendo Cáceres}

Este asentamiento aglomerado se emplaza a 2.5 $\mathrm{km}$ al oriente del campo de petroglifos de Ampajango, sobre una angosta terraza que corre entre el río homónimo y un cauce estacional, a $2100 \mathrm{~m} . \mathrm{snm}$. Hace cuatro décadas un equipo de la Universidad de Rosario efectuó excavaciones en algunos recintos, aunque no se publicaron detalles de los trabajos (Lorandi 1966: 52-53). Las construcciones principales cubren una superficie mínima de 5 ha, con sectores delimitados por muros que cortan transversalmente la terraza y circuitos de circulación planificados que los recorren.

De acuerdo a las evidencias arquitectónicas y al material cerámico de superficie, el sitio registró una prolongada ocupación. El sector IV, se ubica en el extremo noroeste de la terraza, lindante con construcciones actuales, y corresponde a una instalación de desarrollos local e incaico. Las estructuras fueron levantadas con pirca doble sin relleno, utilizándose bloques irregulares y aprovechando, en ocasiones, peñascos in situ. A poca distancia del asentamiento se encuentran otros conjuntos de construcciones de génesis imperial: hacia el sur, Ampajango IV, en donde se recuperaron en superficie restos de alfarería de tipos incaicos; al norte está Casas Viejas, un conjunto constructivo con paredes cuidadas y emplazado sobre un promontorio. Hacia la parte baja del valle los restos de construcciones se encuentran destruidos por ocupaciones modernas, siendo de destacar canchones de cultivo que acompañan el curso del río Ampajango. Sobre la terraza baja del río, a la altura del sector IV, se observan recintos de siembra rectangulares alargados que abarcan 1.5 ha y tres núcleos de canchones similares fueron detectados aguas arriba (Tarragó et al. 2001 Ms). Dos rampas escaleradas de $2 \mathrm{~m}$ de ancho descienden desde la terraza a la playa y la empinada ladera fue reforzada con líneas de muros de contención construidos con grandes bloques desbastados.

El área más prominente del sector incaico de Ampajango II es su plaza central, de planta poligonal y que, en su extremo noreste, posee una rampa de $3.5 \mathrm{~m}$ de ancho que lleva a Casas Viejas. La plaza fue demarcada por un muro de circunvalación de pirca doble sin relleno. El espacio interior se muestra despejado por intensos trabajos de despedrado y, en el borde occidental, a una cota levemente más baja, se ubica media docena de recintos de tendencia rectangular. De igual modo, hacia el noroeste se presenta un gran recinto de forma irregular, que también fue sometido a despedrado en su parte central y al que se accede por una estrecha puerta de $1 \mathrm{~m}$ de ancho (Figura 14). En la esquina noroeste de la plaza se emplazó una forma muy particular de ushnu, conformado por un enorme peñasco de $10 \mathrm{~m}$ de largo en sentido este-oeste, $4 \mathrm{~m}$ de ancho en sentido norte-sur y $3 \mathrm{~m}$ de altura promedio, que fue rodeado por plataformas escaleradas que lo enmarcan. La cara sur del peñasco, que mira hacia la plaza y, más allá, hacia las cumbres nevadas de la cadena del Aconquija, presenta dos líneas de plataformas realizadas con rocas canteadas, mientras que una rampa permite ascender a la cúspide plana de la gran roca por su lado norte (Figura 15).

Fueron excavadas dos cuadrículas exploratorias, al sureste y noreste de la plaza, ubicándose las superficies de ocupación debajo de las rocas de derrumbe y obteniéndose un fechado radiocarbónico (Beta 146370). Las muestras cerámicas de superficie y de excavación ofrecieron tipos tardíos como Famabalasto Negro sobre Rojo, Santa María Bicolor, Belén-Santa María, Quilmes Rojo Grabado e Inca, entre ellos Inca Paya y Cusco Policromo (Figura 6, 1). Corresponde mencionar 


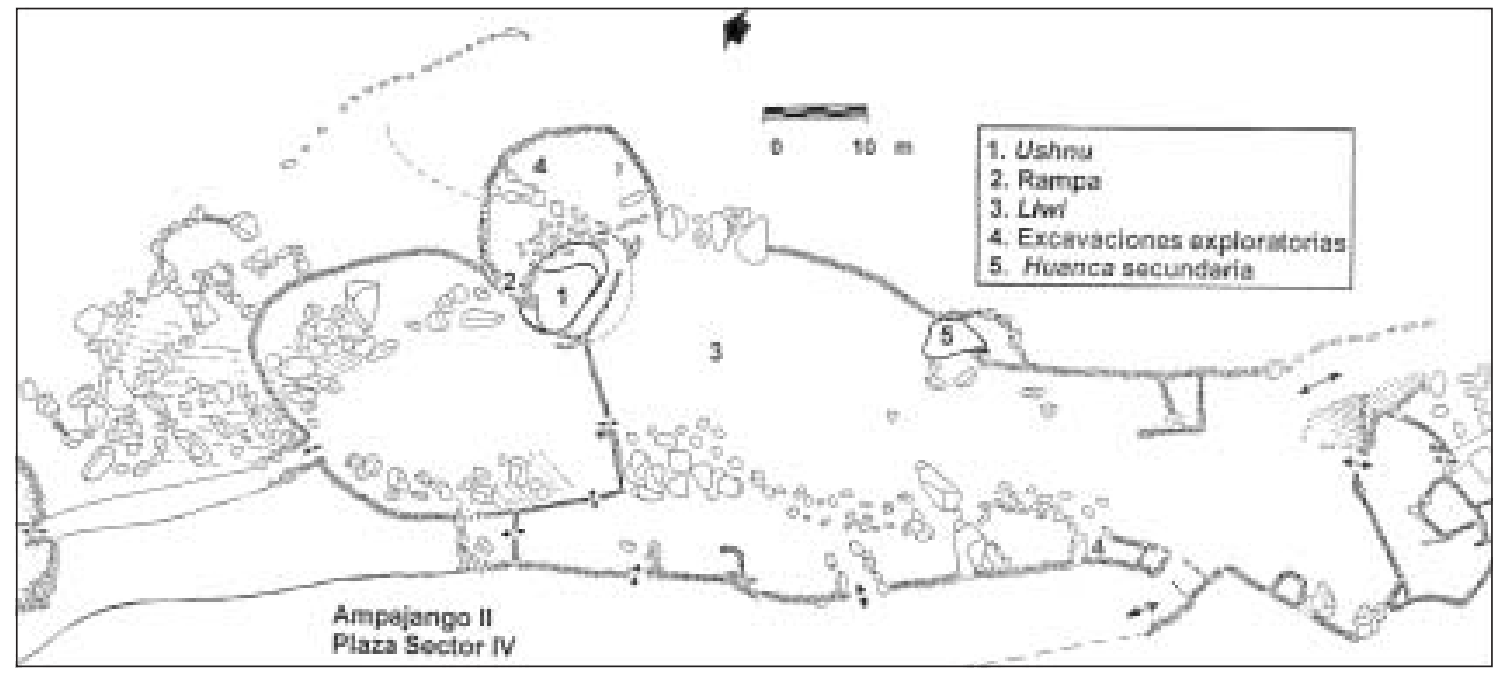

Figura 14. Plaza del sector IV de Ampajango II

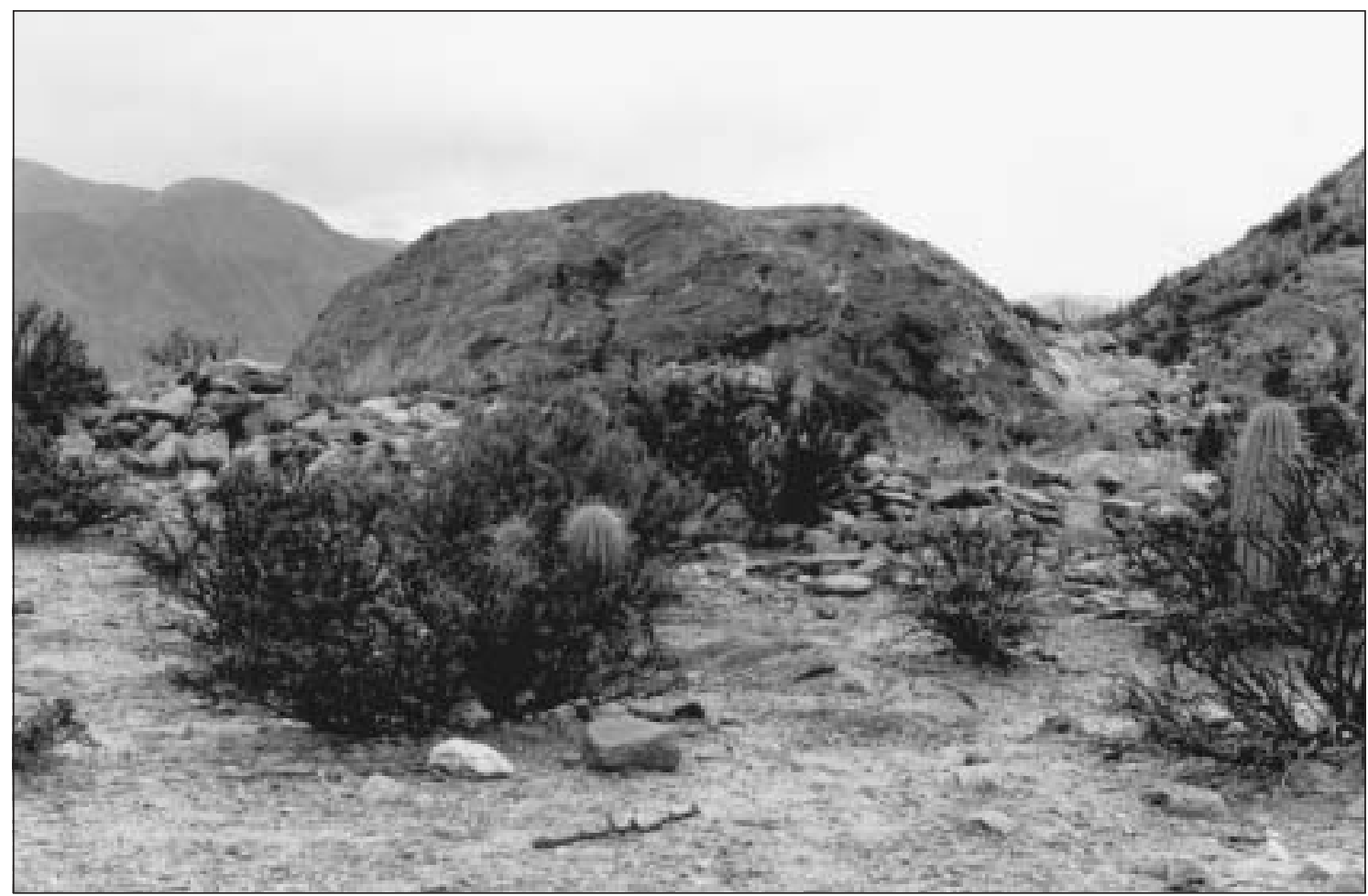

Figura 15. Ampajango II. Vista del ushnu de la plaza del Sector IV.

que en una anterior prospección en la plaza había sido recuperado en superficie un $l i w i^{3}$ de bronce estañífero de clara raigambre incaica (González y Palacios 1996). Cabe señalar que en excavaciones

\footnotetext{
Pequeña bola para cazar pájaros.
}

de la década de 1960 de un recinto asociado a una piedra grabada de estilo "geométrico intrincado" en la zona cercana a El Ingenio, se obtuvo una muestra de carbón que ofreció un fechado que se remontó a 670 \pm 85 AP (Cigliano 1966), lo que permite establecer una continuidad de ocupación en la zona desde épocas preincaicas. 


\section{Loma Rica de Shiquimil}

Este poblado es de los primeros registrados en la historia de la arqueología de la región y se ubica sobre una meseta de difícil acceso, a $6 \mathrm{~km}$ al sureste de San José, entre las localidades de Entre Ríos y Andalhuala. Ambas localidades cuentan con cursos de agua permanentes. Durante las investigaciones realizadas por nuestro equipo en Loma Rica, fue revisado el plano levantado por Weiser en 1923 y publicado por A. R. González (1954). Las construcciones cubren 2.45 ha, con 189 recintos de muros dobles de pirca seca, dos plazas, cada una de ellas en los extremos este y oeste, 15 espacios de circulación y una calle norte-sur que segmenta al poblado en dos. Los anteriores estudios habían puesto énfasis en el análisis de las condiciones culturales y cronológicas del Período de Desarrollos Regionales Inicial, muy poco conocido hasta comienzos de la década de 1970 y representado por abundantes evidencias de material funerario (Perrota y Podestá 1975, 1978), así como por muestras de cerámica de superficie recuperadas en el interior de los recintos (Tarragó et al. 1988). Sin embargo, existen otros datos que apuntan a señalar una prolongada ocupación, de al menos 600 años, en el asentamiento y en el área de influencia de Entre Ríos y Yapes (Tarragó 1995).

Una de las plazas, la oriental, muestra signos de remodelaciones muy tardías, que le otorgaron una planta trapezoidal y ángulos rectos en la unión de los muros. También habría sido modificado un grupo de recintos aledaños, imprimiéndoles plantas rectangulares mediante cuidadas técnicas constructivas. Obtuvimos un fechado sobre una muestra de carbón vegetal extraída de un recinto erigido en el sector oriental, de acceso a la plaza (ver Tabla 1). Es pertinente mencionar que Liberani y Hernández (1951 [1877]: Lám. 23), en sus trabajos en el siglo XIX, entre los materiales funerarios que fueron recuperados en el lugar, consignaron un jarro con asa lateral de clara estirpe incaica (Figura 16). La colección existente en el Museo de La Plata, resultado de las exploraciones de Metfhessel en la Loma Rica y alrededores, luego revisada por Chiappe (1965), muestra un predominio de urnas Santa María Bicolor de "alto cuello y reducido cuerpo subglobular" en los cementerios al pie de la Loma y en la Quebrada de Shiquimil, habiéndose registrado otras vasijas, como la variedad santamariana $\mathrm{Ne}$ -

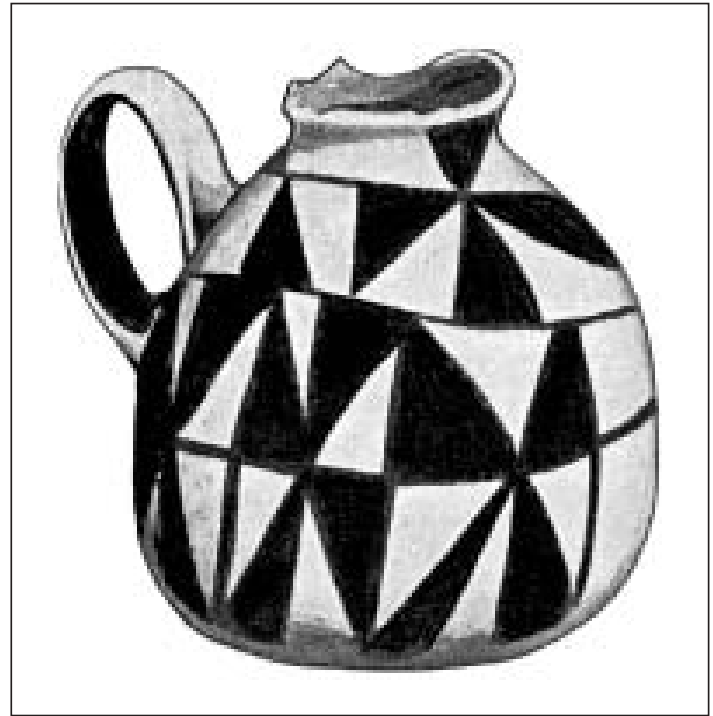

Figura 16. Jarro incaico ilustrado por Liberani y Hernández (1951 [1877]), procedente de Loma Rica de Shiquimil.

gro sobre Rojo, adjudicada a momentos muy tardíos, Famabalasto Negro sobre Rojo (Outes 1907: Plancha II, 3 y 5) y Caspinchango, por lo cual Chiappe (1965: 75) postuló una ocupación de la Loma Rica "durante la segunda mitad del siglo $\mathrm{XV}$, perteneciendo por consiguiente a los últimos períodos de la Cultura Santamariana, con influencia incaica”. Perrota y Podestá $(1975,1978)$, además, describieron contextos funerarios excavados por Weiser en el cercano "Antigual de la Quebrada de Shiquimil", los que incluían puntas de proyectil de hueso y cuentas de vidrio, elementos que sugieren la adscripción tardía de algunas de las tumbas. Este conjunto de evidencias permite plantear que el proceso local se entrelazó en los momentos prehispánicos finales con la dominación incaica y la colonial temprana, en un caso similar a otros de los asentamientos tratados.

Relevante para la problemática abordada es indicar que a $2 \mathrm{~km}$ al sureste de San José se encuentra el poblado de Loma Redonda, ya explorado por Weiser (A. González 1954: 81, 86; Perrota y Podestá 1975: 407). En la década del 60, un equipo de la Universidad de Rosario realizó un relevamiento expeditivo de las construcciones emplazadas en la cima de la terraza que se eleva $100 \mathrm{~m}$ por sobre el nivel del valle, registrándose 57 estructuras aisladas o agrupadas en unidades de dos o tres recintos rectangulares, a veces con 
un recinto circular adosado (Tarragó 1964 Ms). Nuestras prospecciones en la zona permitieron constatar que el sitio se encuentra actualmente en gran parte alterado por la construcción de un calvario. Las recolecciones de alfarería en superficie realizadas al pie de la ladera norte nos permitieron identificar, junto a los tipos locales predominantes, algunos fragmentos Inca Provincial (Kriscautzky 1999: 99-100).

\section{Loma Alta de Shiquimil}

Emplazado a un kilómetro y medio al oriente de la mencionada Loma Rica de Shiquimil, consta este asentamiento de dos conjuntos constructivos erigidos sobre sendas elevaciones del relieve terciario de la zona, adyacentes y separados por una profunda depresión. Al pie de estas elevaciones se presenta una angosta quebrada con un ojo de agua permanente de importante caudal. Un registro expeditivo de las construcciones fue realizado por Caviglia en 1986 (Copello $1991 \mathrm{Ms}$ ).

El conjunto constructivo denominado A ocupa la totalidad del espacio plano de una loma, cuyo borde fue delimitado por un muro doble sin relleno interior realizado con rocas de distintos tamaños y con escasa preparación previa. Se conformó así una gran plaza poligonal, cuyas dimensiones máximas son $33 \mathrm{~m}$ por $24 \mathrm{~m}$. Fuera de la plaza, al sur, se levantó un recinto subcircular, con un diámetro máximo de $8 \mathrm{~m}$. Otro recinto circular, de $4 \mathrm{~m}$ de diámetro, fue construido junto a una abertura del muro perimetral, hacia el este. En la esquina oriental de la plaza se relevó un círculo de grandes peñascos, en cuyo centro se encuentra una piedra de mortero. La pendiente del lado norte de la plaza inmediatamente debajo de la cima de la loma presenta tres niveles aterrazados, demarcados con líneas de pirca simple, divididos a su vez por muretes de pirca doble sin relleno. En superficie no fueron recuperados más que escasos fragmentos de alfarería ordinaria, tal vez porque, como fuera planteado, puede tratarse de un "área agrícola para propósitos especiales".

El grupo B de construcciones se levanta sobre una loma cercana, pero cuya cima es de mayores dimensiones. Los pircados se distribuyen en una franja de $50 \mathrm{~m}$ por $400 \mathrm{~m}$, consistiendo en grandes canchones con recintos circulares y rectangulares en su interior. Las características constructivas de los muros son similares a las verificadas en el grupo A. El mejor conservado de los canchones cubre 0.5 ha, con una estructura rectangular adosada interiormente a uno de los muros perimetrales. Los fragmentos de alfarería son relativamente abundantes en superficie, y junto a los tipos locales dominantes fueron identificados tiestos Inca Provincial. En dirección sureste, en el mismo relicto de terraza cuaternaria y llegando a la localidad de Andalhuala, tuvimos oportunidad de realizar un relevamiento preliminar de construcciones prehispánicas que cubren una amplia superficie y constituyen, mayoritariamente, estructuras agrícolas con canales de riego, a las que asociaban abundantes fragmentos de alfarería correspondientes a tipos locales e incaicos (Tarragó et al. $2001 \mathrm{Ms}$ ).

Quebrada de Jujuil

En la Quebrada de Jujuil o Jojoy (Perrota y Podestá 1978: Mapa 2), cerca de Lorohuasi, Weiser y Wolters excavaron tres lugares funerarios en 1923 y 1924. En el denominado Cementerio I del Río Seco de los Cancino, cuyos contextos fueron analizados por Baldini y Albeck (1983), además de los materiales de origen europeo que aparecieron en todas las sepulturas, tales como collares de vidrio y objetos de hierro, las autoras señalaron la asociación de alfarería de carácter incaico y de manojos de puntas de flechas óseas conocidas como "cola de golondrina". En la tumba I, que contenía tres esqueletos de adultos, uno de los platos recuperados "tendría ciertas reminiscencias incaicas por el motivo de los rombos" (Baldini y Albeck 1983: 552). En la tumba IV, con ocho individuos inhumados, otro plato presentaba en su interior "un motivo que se asemeja al ilustrado por Ambrosetti (...) procedente de la Casa Morada de La Paya. La decoración externa se relaciona con los motivos de la cerámica IncaPaya" (Baldini y Albeck 1983: 552). De la tumba VIII, con cinco individuos, las autoras ubicaron una ollita de un tipo de neta influencia inca y, en la tumba IX, con cuatro esqueletos, dos de los platos presentaban motivos también de filiación incaica, aunque más lejana (Baldini y Albeck 1983: 553).

\section{Caspinchango}

La localidad arqueológica de Caspinchango, conocida en particular a partir de los trabajos de Weiser y de Debenedetti (1921), se ubica a unos 
$15 \mathrm{~km}$ al oriente de la ciudad de Santa María y comprende diversos sitios distribuidos en una superficie de $20 \mathrm{~km}^{2}$ (Arocena et al. 1960: 84). Se trata, en general, de andenes y cuadros de cultivo entre los que se esparcen grupos discretos de construcciones. Las agrupaciones más densas y con mejor conservación fueron designadas, por el equipo de la Universidad de Rosario que trabajó en el lugar, El Monte, El Ciénago, Valle Viejo y Sur de Monte Redondo, a los que se suman los asentamientos sobre mesetas ya conocidos, como La Maravilla-Masao y El Pabellón. Methfessel, en sus viajes de 1887 y 1889, recorrió Caspinchango (Chiappe 1965: 7) y parte de los materiales recolectados fue ilustrada por Outes, publicándose la figura de un aríbalo de adscripción tardía (Outes 1907: Lám II, 10) procedente de Pabellón, probablemente el sitio homónimo de Caspinchango (Figura 4c). Este indicio se ajusta a la clara ocupación colonial temprana que demuestran los cementerios Rico y Monte Redondo analizados por Debenedetti (1921). La revisión de esta publicación, sin embargo, indica que las urnas santamarianas (que Debenedetti no trató ni ilustró), y que se encontraron anexas a las cámaras sepulcrales de adultos, no serían remanentes de antiguos cementerios, como postulara, sino de la misma época de las cámaras, poniendo en evidencia un sugestivo proceso en el cual los adultos se inhumaron con símbolos de prestigio social de raíz europea (cinturones de cuero con hebillas, cuchillos de hierro, collares con cuentas de vidrio), mientras que en el caso de los infantes se reinvindicaba la tradición cultural santamariana. Baldini y Albeck (1983: 558-559) expresaron que "no es válida la ausencia de rasgos de filiación incaica remarcada por Debenedetti” y, si bien este autor no citó la presencia de elementos santamarianos junto a los de tipo Caspinchango, detectaron en los contextos funerarios asociaciones entre la alfarería de ambas modalidades.

El equipo de la Universidad de Rosario llevó a cabo excavaciones en varios sitios. En El Monte, en superficie registraron fragmentos de alfarería de tipos incaicos, Rojo Pulido y Negro sobre Rojo, así como Yocavil Tricolor. En la excavación de una unidad de vivienda también fueron identificados tipos locales como San José y Santa María, además de fragmentos más tempranos asignables a La Aguada y Candelaria. Muestras similares fueron obtenidas en nuestras prospecciones en el lugar. Esta información, sumada a la proporcio- nada por otros autores, sugiere que el área experimentó una prolongada ocupación, desde momentos agroalfareros tempranos hasta el contacto hispano-indígena, de modo similar a lo observado en Pajanguillo, Ampajango, Shiquimil y Jujuil.

\section{Dominantes, dominados y viceversa}

Las evidencias incaicas registradas hasta el momento en el sur del valle de Yocavil, según fuera reseñado, asumen variadas expresiones, desde obras de infraestructura hasta hallazgos minoritarios de alfarería. En algunos asentamientos el Imperio parece haber desplegado con mayor aplicación su reconocida capacidad de recreación del paisaje a través de la arquitectura, como fundamento material de un nuevo orden (Gallardo et al. 1995: 166). Cerrando el valle, encontramos la única ocupación imperial pura, el tambo de Punta de Balasto. En un radio de $4 \mathrm{~km}$ de esta instalación se ubican poblados de génesis local en los cuales los administradores cusqueños promovieron ocupaciones focalizadas, como es el caso de Bajo Mendocino, Bicho Muerto y Pajanguillo. Ampajango II es el poblado que, después del tambo, muestra rasgos más claros de la presencia imperial. Subiendo por el valle hacia el norte la situación torna a hacerse diferente. Descontando la posta de Fuerte Quemado y sus sectores reocupados, en la franja que abarca Las Mojarras-Rincón Chico-Famatanca, la evidencia arquitectónica se confunde con las prácticas locales y los hallazgos de alfarería son minoritarios en las muestras analizadas. Algo similar ocurre en Loma Rica, Loma Alta, Quebrada de Jujuil y Caspinchango, asentamientos que, como Ampajango II, muestran prolongadas ocupaciones previas.

El tambo de Punta de Balasto, instalado sobre el camino troncal que recorría el fondo del valle, habría actuado como una estación de control del tránsito de personas y el tráfico de bienes dentro del entramado de instalaciones administrativas del sur del Collasuyu (L. González 1999). En el tambo confluían tres importantes ramales, que conectaban, respectivamente, con los importantes centros de Hualfín y Shincal, con los distritos mineros de Capillitas-Atajo y con el establecimiento de Nevados del Aconquija y sus estaciones intermedias. Además de las consideraciones funcionales, la instalación del tambo en un punto del paisaje previamente no ocupado pudo contener un 
fuerte contenido simbólico, materializando la apropiación del espacio regional y su reorganización en torno a los principios del orden estatal.

El asentamiento de Bicho Muerto, asociado al tambo, es un clásico caso de ocupación parcial de una población prexistente (Williams 2000: 74). La información de los cronistas indica que el Morro Blanco, a cuyo pie se levanta el asentamiento, constituía una venerada huaca en tiempos prehispánicos tardíos (Piossek Prebisch 1984). Su potencial simbólico habría estado incrementado por los depósitos minerales que albergaba la formación y que abastecían a los establecimientos metalúrgicos de El Trapiche y Fundición Navarro (L. González 2000). Respecto de Cerro Mendocino, algunas de las construcciones de la cima, como los torreones, presentan características constructivas que podrían interpretarse como correspondientes a los cánones incaicos, mientras que las estructuras al pie del cerro (el Núcleo A y la gran plaza) señalan con mayor firmeza la presencia imperial. Encontramos sugestivo que estas dos últimas construcciones hayan sido emplazadas en la entrada a la quebrada de acceso al poblado alto. No tenemos evidencias como para sostener que, bajo la administración cusqueña, se haya forzado a los grupos locales a abandonar la fortaleza, como ha sido referido para otros lugares del Tawantinsuyu (Hyslop 1990: 151-152), pero es posible que durante esa época la circulación vertical hubiera estado controlada y aún restringida.

En el caso de Ampajango II-Rosendo Cáceres pudo resultar de importancia estratégica que la instalación se encontrara a mitad de camino en un corredor natural que conduce a los pasos que atraviesan la cadena del Aconquija hacia la vertiente tucumana. De igual modo, las aguas permanentes del río Ampajango proporcionaron la base para cultivos intensivos que habían sido desarrollados desde tempranas épocas prehispánicas. La presencia incaica en este lugar podría explicarse en el marco de los objetivos de incrementar la producción agrícola zonal, redimensionando la infraestructura en tal sentido. Cabe subrayar que la ocupación parece haber implicado, de igual modo, una transformación y aumento en la escala del ceremonialismo vinculado tanto con los ritos de agua y las prácticas agrícolas como con la integración del espacio a la organización estatal. El ushnu que preside la plaza del sector IV presenta características conocidas en otras instalaciones del territorio del Tawantinsuyu (Hyslop 1990: 69-83; Meddens 1997). En tal sentido, ha sido planteado que el gran peñasco, orientado hacia las cumbres nevadas, constituía, en épocas previas, una huanca de alcance local vinculada con el culto al complejo ancestros-montañas-fertilidad de la naturaleza. Los administradores cusqueños aprovecharon la sacralidad del monumento, lo redimensionaron y, sin que perdiera relación con las divinidades tutelares de la región, le otorgaron una mayor significación política, sustrayendo del control local su potencial simbólico e incorporándolo a la estructura religiosa estatal (Tarragó et al. $2001 \mathrm{Ms}$ ).

El drástico cambio en las condiciones sociopolíticas también se refleja en la remodelación del espacio que ocupa la plaza, con importantes trabajos de despedrado y, probablemente, la demolición de estructuras previas para crear tanto áreas de congregación como vías de circulación pautadas, todo lo cual sugiere un intento por restringir y controlar el paisaje ceremonial (Tarragó et al. $2000 \mathrm{Ms}$ ). Sin embargo, debe subrayarse la intencionalidad del Estado en conservar la modalidad arquitectónica local. Debe tenerse presente, además, que la zona probablemente acreditaba un alto valor simbólico a nivel regional desde siglos antes: en la inmediata cercanía del asentamiento se encuentran las conocidas rocas grabadas de Campo del Ingenio y Mesada Barrera. En Ampajango II, en uno de los sectores correspondientes al desarrollo exclusivamente local, se ha registrado una roca grabada de similares características a las de aquellos sitios. Es posible que en el asentamiento hubieran convivido las prácticas cúlticas tradicionales con las oficializadas por el Estado, teniendo en cuenta la conducta tolerante que el incario mostró en ese aspecto.

A partir del modelo de organización que fuera planteado para los momentos previos a la llegada incaica, en el cual el poblado de Rincón Chico actuaba como cabecera política de un sistema de asentamiento que articulaba a otras instalaciones del sur del valle y de las cuales extraía una parte importante de los recursos de subsistencia, no parece casual que sea en su área de acción inmediata en donde el registro imperial aparezca como más sutil. La detallada secuencia radiocarbónica obtenida para la localidad no deja lugar a dudas que el poblado se mantuvo activo hasta la ocupación española. Las evidencias incaicas más claras 
parecen concentrarse en conjuntos constructivos del fondo del valle, es decir, en el sector más marginal al centro poblado ubicado en la serranía. Los sitios 12, 13, 14 y 15 se levantaron en el límite del antiguo bosque de algarrobos que acompañaba el curso del río principal. Como adelantáramos, el sitio 15 albergó un taller metalúrgico que había alcanzado un alto nivel de actividad y la ocupación incaica se tradujo en una intensificación de la producción de metales, con fundiciones masivas a través de hornillos del tipo huayra.

Por otra parte, los sitios mencionados se alineaban a la vera de uno de los tramos troncales del camino incaico que atravesaba la zona. Este camino llegaba desde el norte uniendo importantes postas, como Tolombón, Pichao, Quilmes y Fuerte Quemado (Hyslop 1990: 254). Con toda probabilidad Las Mojarras, con su pucara en lo alto del cerro y sus construcciones al pie, participaba de este circuito. La ruta, luego de pasar por Rincón Chico, llegaba a Medanitos-Famatanca, desde donde se desprendía un ramal que conducía al otro lado de la Sierra del Cajón, conectando con poblados como el de Famabalasto. Posteriormente, el camino troncal cruzaba el río Santa María a la altura de San José Banda y continuaba hacia el sur junto a su ribera oriental (ver Figura 1). Es posible que en esa vertiente se uniera con un brazo que vinculaba con el fértil valle de Tafí. La posición del sitio 15 dentro del sistema vial tenía sus consecuencias para la organización de la producción metalúrgica. Por un lado, se aseguraba una eficiente movilización de materias primas minerales, teniendo en cuenta que estos materiales, en particular el óxido de estaño, debían transportarse desde una distancia más o menos considerable. De igual modo, la evacuación de productos desde el taller para su eventual distribución regional o extrarregional también habría sido más fácil. Por último, todos los aspectos de la producción metalúrgica quedaban con mayor claridad sujetos al control estatal (L. González 2001). La planificación espacial de la organización productiva, con su específica logística de aprovisionamiento de materias primas, eficaz movimiento de bienes y supervisión de los talleres, que fuera postulada a partir de la evidencia de Rincón Chico, se fortalece con los datos del área de actividades de fundición registrada durante los trabajos en LM 1 y del contexto descrito para Fuerte Quemado, ambos casos con asociación a la ruta imperial. Además del 15, los otros tres sitios $(12,13$ y 14), fundados por poblaciones locales en épocas preincaicas, fueron parcialmente remodelados para adecuarlos a los intereses estatales.

Como ocurriera en Ampajango II, en Rincón Chico la dominación aparejó modificaciones de menor o mayor magnitud en la escala y orientación de las prácticas ceremoniales. Por ejemplo, para el sitio 14, donde fue estudiado un contexto de probable elaboración de chicha en grandes cantidades (Tarragó et al. 1999), se ha planteado que las actividades estuvieron vinculadas con la realización de festejos periódicos a través de los cuales se renovaban las relaciones de poder entre el Estado y los líderes locales. De igual modo, el vasto escenario ceremonial del poblado central en la Quebrada del Puma, parece haber sido redimensionado para convocar un mayor número de asistentes. En este aspecto, la información etnohistórica apunta a indicar que, hacia el momento del contacto con el español, Rincón Chico albergaba una muy venerada huaca (Lorandi y Boixadós 1988: 350-351). En otra oportunidad hemos propuesto que este lugar sagrado estaba centrado en la Quebrada del Puma, espacio en el cual la remodelación del paisaje no sólo se orientó a propiciar la comunicación con las deidades tutelares, sino también a naturalizar la división entre élites y comunes (Tarragó y González 2000 Ms). A la llegada de los incas, el lugar probablemente constituía un centro de peregrinación que convocaba a poblaciones cercanas y la administración cusqueña, lejos de combatir tales prácticas, las habría fomentado, apropiándose de la sacralidad del espacio y de su capacidad intrínseca para difundir principios ideológicos fundantes, en este caso, orientados hacia los intereses del Estado. A diferencia de lo acontecido en Ampajango II, las huanca del pie del cerro, como dijéramos, no parecen haber sido intervenidas.

\section{Conclusiones}

Los datos reseñados muestran que la dominación incaica en el sur del valle de Yocavil estuvo focalizada en determinados espacios y aspectos productivos, lo cual se refleja en la variabilidad del registro arqueológico detectado. Todo apunta a indicar que uno de los principales objetivos perseguidos por el incario en la región (sin desdeñar la producción de otras artesanías) parece haber sido el de aprovechar la capacidad técnica de los especialistas en metalurgia, aumentando el 
nivel de las actividades e insertando la producción en un entramado más amplio que abarcaba a otras instalaciones de una amplia región. En tal sentido, las ocupaciones en el extremo meridional de la sierra del Cajón pueden haberse vinculado con la explotación de depósitos minerales localizados en la misma sierra y con su procesamiento primario (L. González 2000), complementando la movilización de materiales extraídos de yacimientos más lejanos, como Capillitas-Cerro Atajo, unos $40 \mathrm{~km}$ al sur.

Aunque la información disponible es aún incompleta, al parecer, la producción agrícola fue otro aspecto económico fomentado. No obstante, es probable que no se pretendiera generar excedentes para su exportación a otras regiones, sino que la intensificación en la explotación de los recursos de la tierra se relacionara con la necesidad de sostener el aparato administrativo local y, sobre todo, con la mayor dedicación exigida de los operarios que se ocupaban de las tareas minero-metalúrgicas. En ese sentido, el sistema productivo vigente habría sido redimensionado, disponiéndose un mayor control en las cuencas fértiles del lado oriental del valle: Ampajango, Andalhuala, Entre Ríos, Jujuil y Caspinchango.

La discreción y las características de la ocupación incaica en algunos sectores del valle sugieren una articulación relativamente pacífica con las élites políticas locales. Esto no significa la disolución del estado de conflicto inherente a las sociedades no igualitarias. El reconocimiento político de los líderes locales conllevó que los fundamentos de su autoridad fueran desplazados desde el ámbito local al estatal. En última instancia, el poder emanaba del Cusco y es presumible que las nuevas condiciones hayan disparado nuevas maneras de competencia sociopolítica en el seno de las formaciones nativas, con distintos grupos que operaron para hegemonizar posiciones ventajosas en la reestructuración. Si se comparan las dos poblaciones más complejas del área tratada, Fuerte Quemado y Rincón Chico, pueden observarse ciertas diferencias que se relacionarían con operatorias singulares frente a la dominación inca. La composición de la muestra cerámica de excavación en Fuerte Quemado, analizada por Kriscautzky (1999: 143-157), incluye porcentajes relativamente elevados del tipo inca local Negro sobre Rojo (entre $14 \%$ y $36 \%$ en recintos del sector IV) en relación a las vasijas Santa María Negro sobre Cre- ma en sus diversas variedades. Este estilo resulta de interés, porque aparece como otro tipo inca mixto, con cualidades de pasta y algunos diseños de raigambre Santa María-Belén, combinados con otros que se cruzan con el Inca Paya y aún con el Inca Humahuaca (González y Tarragó 2000 Ms). En cambio, en Rincón Chico, como se viera anteriormente, la aparición de cerámica rojo pulido, negro sobre rojo sanguíneo (sensu Bruch 1911) e Inca Paya es muy baja o está ausente en numerosas muestras, predominando con amplitud el Santa María Bicolor. En cuanto a los conjuntos arquitectónicos, las instalaciones de Fuerte Quemado, son, al igual que en Rincón Chico y Las Mojarras, extensas e intrincadas, involucrando espacio altos y bajos y estructuras ceremoniales en la parte superior de dos morros, características que sugieren una tradición cusqueña más definida. En cambio, en Rincón Chico el Estado habría preferido exaltar antiguas huaca regionales, estableciendo un nexo con las tradiciones ancestrales de las poblaciones locales.

La organización económica vigente pudo ser reorientada hacia los intereses estatales sin apelar a mecanismos de control que demandaran inversión en personal represivo o infraestructura. Los datos sugieren que la ocupación inca no incluyó la implantación de grupos de poblaciones ajenas a la región para asegurar condiciones de estabilidad política. Por lo general, estas situaciones son inferidas a partir de la distribución de tipos cerámicos Famabalasto Negro sobre Rojo y Yocavil (Lorandi 1991: 227). En nuestro caso y descontando Punta de Balasto, las frecuencias cerámicas en los distintos sitios muestran un predominio de materiales santamarianos y Santa María-Inca, siendo aquellos tipos muy minoritarios o aún inexistentes. Habida cuenta que al momento no hay evidencias para sostener que estas alfarerías fueron fabricadas en el valle, su escasa representación sugiere que los fragmentos registrados corresponden a piezas movilizadas desde otros lugares (Williams 2000: 69-70). Debe consignarse que la mencionada pobreza se correlaciona, sugestivamente, con la continuidad de la cerámica Famabalasto Negro Grabado y la expansión territorial de su distribución. De hecho, ha sido registrada en emplazamientos incaicos de envergadura y relativamente distantes, tales como Potrero Chaquiago, Shincal y Potrero de Payogasta. Al respecto, se propuso que los administradores incaicos habrían intervenido en su movili- 
zación a partir del prestigio que acreditaban los materiales, tal como parece haber ocurrido con los bronces santamarianos (González y Tarragó 2003). Por otra parte, desde una óptica productiva, la introducción de grupos alóctonos no hubiera sido la mejor de las decisiones. En el caso de las actividades agrícolas, las áreas implicadas se encontraban en operación desde mucho tiempo antes y todo indica que la administración inca, más allá de fomentar la escala de salida de productos, se sirvió de la estructura de trabajo vigente, con la mano de obra ya en operación. Para las actividades minero-metalúrgicas, un recambio poblacional hubiera tirado por la borda la experiencia técnica de siglos que, según surge de los datos obtenidos en el taller del sitio 15 de Rincón Chico, fue acumulada por generaciones de operarios.

Los criterios económicos imperiales fueron impuestos en forma dialéctica con una redefinición del aparato simbólico surandino no sólo en las representaciones materiales, sino sobre todo en la escala ceremonial y ritual. No obstante, la ideología dominante no habría permeado de igual modo a la totalidad de los miembros de la sociedad. Así como se mantuvieron los estilos expresivos y tecnológicos en la producción de bienes de bronce, la cerámica santamariana mantuvo vigencia con escasas modificaciones (González y Tarragó 2003), una situación que puede estar informando tanto de la fortaleza del aparato ideológico tradicional como de la multiplicación de fenómenos de resistencia cultural y la adecuación a un nuevo orden manteniendo una diferenciación social y simbólica. Como se ha planteado oportunamente, el estilo santamariano llegó a convertirse en un "estilo de época" que circuló por amplios espacios de los Andes, al sur del Cusco y más allá, en las mesetas patagónicas (Tarragó et al. 1997).

En suma, el caso estudiado pone de manifiesto que la ocupación inca en el sur del valle de Yocavil fue mucho más intensa que lo que conocíamos, pero con un reflejo arqueológico que no se ajusta estrictamente a los rasgos "típicos" a partir de los cuales suele evaluarse la presencia imperial en los Andes Meridionales. Las cualidades de este registro arqueológico señalarían, por una parte, la estrategia de la ocupación imperial en la región, destacando las áreas con un valor particular para los objetivos político-económicos centrales y que, en consecuencia, se juzgaron como adecuadas para ser desarrolladas mediante la inversión en infraestructura. Pero, de igual modo, estas cualidades estarían dando cuenta de las condiciones sociopolíticas y organizativas vigentes, las cuales, en algunos casos, podrían haber sido funcionales a la administración cusqueña y hacer innecesaria la inversión de energía en obras más o menos monumentales, mientras que en otros podrían haber actuado como focos de resistencia en los que la imposición de las normas y de la cultura material del Imperio se diluyeron.

La arrolladora dinámica de expansión del Estado incaico parece haber arrastrado, en ciertas oportunidades, el enfoque de las investigaciones arqueológicas en los Andes Meridionales, otorgando un casi exclusivo protagonismo a las aspiraciones del Cusco y dejando en un oscuro segundo plano a los procesos históricos de las sociedades que poblaban las regiones incorporadas al Tawantinsuyu. Desde una óptica alternativa, en la que se privilegia el estudio de los procesos de cambio a partir de la posición de las sociedades dominadas, sostenemos que los intereses particulares de las élites políticas locales, el sistema de representaciones y la dinámica de los conflictos faccionales, constituyeron factores activos que matizaron el modo en que la dominación estatal fue plasmada. En el proceso de ocupación territorial no sólo los planificadores cusqueños exhibieron una amplia flexibilidad para desplegar sus objetivos particulares. También las formaciones sociales abarcadas desarrollaron sus propias estrategias para no perder espacio dentro de las nuevas condiciones. 


\section{REFERENCIAS CITADAS}

AROCENA, M., G. DE GASPERI y S. PETRUZZI, 1960. Caspinchango. En Investigaciones arqueológicas en el valle de Santa María, pp. 81-109. Publicación 4, Instituto de Antropología, Universidad Nacional del Litoral, Rosario.

BALDINI, L. y M. ALBECK, 1983. La presencia hispana en algunos cementerios del valle de Santa María, Catamarca. En Presencia hispánica en la arqueología argentina 2, pp. 549-566. Facultad de Humanidades, Universidad Nacional del Nordeste, Resistencia.

BRUCH, C., 1911. Exploraciones arqueológicas en las provincias de Tucumán y Catamarca. Revista del Museo de la Plata V (19).

CARRARA, A., A. M. LORANDI, S. RENARD y M. TARRAGO, 1960. Punta de Balasto. En Investigaciones arqueológicas en el valle de Santa María, pp. 13-41. Publicación 4, Instituto de Antropología. Universidad Nacional del Litoral, Rosario.

CIGLiAnO, E. M., 1966. Contribución a los fechados radiocarbónicos argentinos (I). Revista del Museo de La Plata NS, VI, Antropología 29: 1-16.

COPELLO, R., 1991 Ms. Loma Alta de Shiquimil. Instalaciones agrícolas y fuentes hídricas. Informe PID 3 913303/85, Buenos Aires.

CHIAPPE, D., 1965. Estudio arqueológico de la colección Methfessel del Museo de La Plata. Tesis de Doctorado en Ciencias Naturales, Universidad Nacional de La Plata, La Plata.

DEBENEDETTI, S., 1921. La influencia hispánica en los yacimientos arqueológicos de Caspinchango (prov. de Catamarca). Publicaciones Sección Antropológica 20, Facultad de Filosofía y Letras, Universidad de Buenos Aires, Buenos Aires.

GALLARDO, F., M. URIBE. y P. AYALA, 1995. Arquitectura inca y poder en el pucara de Turi, norte de Chile. Gaceta Arqueológica Andina 24: 151-171.

GONZALEZ, A. R., 1954. Las ruinas de Loma Rica y alrededores. Natura 1: 75-94.

GONZALEZ, L. R., 1995. Blues del Bicho Muerto. Observaciones arqueológicas en el sur del valle de Yocavil. $\mathrm{Pa}$ limpsesto. Revista de Arqueología 4: 97-102.

-1999. Tambo feroz. Nuevos datos sobre el asentamiento de Punta de Balasto y la ocupación incaica en el sur del valle de Santa María (prov. de Catamarca). Actas XII Congreso Nacional de Arqueología Argentina, pp. 222232. La Plata.

2000. Arqueología y etnohistoria: Evidencias de actividades minero-metalúrgicas coloniales en el sur del valle de Santa María (prov. de Catamarca). Actas XIV Congreso Nacional de Arqueología Chilena, pp. 29-47. Copiapó.
-2001. Tecnología y dinámica social. La producción metalúrgica prehispánica en el Noroeste Argentino. Tesis doctoral, Facultad de Filosofía y Letras, Universidad de Buenos Aires, Buenos Aires.

2002. Heredarás el bronce. Incas y metalurgia en el valle de Yocavil. Intersecciones en Antropología 3: 55-68.

GONZALEZ, L. R. y E. CABANILLAS, 2004. Las campanas ovales de bronce del Noroeste Argentino. Revista Andina 38: 225-251.

GONZALEZ, L. R. y R. DORO, 2003. Jardines de piedras. Estructuras ceremoniales en Rincón Chico. Etnia 46-47. En prensa.

GONZALEZ, L. R. y T. PALACIOS, 1996. El volar es para los pájaros. Análisis técnicos de dos piezas metálicas procedentes del valle de Santa María, prov. de Catamarca. Arqueología 6: 25-46.

GONZALEZ, L. R. y M. TARRAGO, 2000 Ms. La ocupación incaica en el sur del valle de Yocavil (Noroeste Argentino). Ponencia presentada en el $50^{\circ}$ Congreso Internacional de Americanistas, Varsovia.

2003. Producción tecnológica e identidad durante el dominio incaico en el Noroeste Argentino. Boletín de Arqueología Pontificia Universidad Católica del Perú 7. En prensa.

GONZALEZ, L. R., R. DORO, P. CORVALAN, N. GROSMAN, M. TANCREDI y A. VARGAS, 2001. Investigaciones en el sitio 12 de Rincón Chico, valle de Yocavil (Catamarca). Actas XIII Congreso Nacional de Arqueología Argentina, pp. 375-383. Córdoba.

GONZALEZ, C., 1996. El criterio monumentalista y su aplicación en la arquitectura inca de Chile central. Boletín de la Sociedad Chilena de Arqueología 23: 33-37.

HYSLOP, J., 1990. Inca settlement planning. University of Texas Press, Austin.

HYSLOP, J. y J. SCHOBINGER, 1991. Las ruinas incaicas de los Nevados del Aconquija (prov. de Tucumán, Argentina). Informe preliminar. En El Imperio inca: Actualización y perspectivas por registros arqueológicos y etnohistóricos, Comechingonia 2, Córdoba.

KRISKAUTZKY, N., 1999. Arqueología del Fuerte Quemado de Yocavil 1. Dirección Provincial de Cultura, San Fernando de Catamarca.

LAFONE QUEVEDO, S. A., 1904. Viaje a los menhires e intihuatana de Tafi y Santa María en octubre de 1898. Revista del Museo de La Plata XI: 123-128.

LIBERANI, I. y J. HERNANDEZ, 1951 [1877]. Excursión arqueológica en los valles de Santa María, Catamarca. Publicación 563, Instituto de Antropología, San Miguel de Tucumán. 
LORANDI, A. M., 1966. El arte rupestre del Noroeste Argentino. Dédalo 11 (4): 15-172.

1991. Evidencias en torno a los mitmaqkuna incaicos en el Noroeste Argentino. Anthropologica 9: 213-243.

LORANDI, A. M. y R. BOIXADOS, 1988. Etnohistoria de los valles Calchaquíes en los siglos XVI y XVII. Runa XVII-XVIII: 263-419.

MEDDENS, F., 1997. Function and meaning of the usnu in Late Horizon Peru. Tawantinsuyu 3: 4-21.

MENDONÇA, O., M. BORDACH y M. GROSSO, 2003. Ocupación territorial e intercambio en el Período Hispano-indígena. Estudio comparado de dos cementerios: RCh21 (Catamarca) y SJ Til 43 (Jujuy). Cuadernos 20: 221-237.

MEYERS, A., 1999. Reflexiones acerca de la periodización de la Cultura Inca: Perspectivas desde Samaipata, oriente de Bolivia. Actas XII Congreso Nacional de Arqueología Argentina, T I: 239-251. La Plata.

MORRIS, C., 1988. Progress and prospect in the archaeology of the Inka. En Peruvian prehistory, R. Keatinge (Ed.), pp. 233-256. Cambridge University Press, Cambridge.

NASTRI, J., 1998. Patrones de asentamiento prehispánicos tardíos en el suroeste del valle de Santa María (Noroeste Argentino). Relaciones de la Sociedad Argentina de Antropología 22/23: 247-270.

OUTES, F., 1907. Alfarerías del Noroeste Argentino. Anales del Museo de La Plata, $2^{\mathrm{a}}$ Serie, I: 5-52.

PERROTA, E. y C. PODESTA, 1975. Arqueología de la quebrada de Shiquimil. Actas I Congreso Nacional de Arqueología Argentina, pp. 405-422. Rosario.

_-1978. Contribución a las culturas San José y Santa María. En Advances in Andean archaeology, D. Browman (Ed.), pp. 525-551. Mouton, París.

PIOSSEK PREBISCH, T., 1984. Relación histórica de Calchaquí. Escrita por el misionero jesuita padre Hernando de Torreblanca en 1696. Ediciones Culturales Argentinas, Buenos Aires.

QUIROGA, A., 1901. Ruinas calchaquíes. Fuerte Quemado. Anales de la Sociedad Científica Argentina LII: 235-243.

RAFFINO, R., 1981. Los incas del Collasuyu. Ramos, La Plata.

_ 1988. Poblaciones indígenas de la Argentina. TEA, Buenos Aires.

REYNOSO, A., 2001 Ms. Las casas del sol poniente: Observación astronómica y arquitectura en el poblado de Rincón Chico, provincia de Catamarca. Ponencia presentada en el XIV Congreso Nacional de Arqueología Argentina, Rosario.

TARRAGO, M., 1964 Ms. Estado actual de la investigación arqueológica en el Valle de Santa María, provincias de Catamarca, Tucumán y Salta.
-1987. Sociedad y sistema de asentamiento en Yocavil. Cuadernos del Instituto Nacional de Antropología 12: 179-196.

1995. Desarrollo regional en Yocavil. Una estrategia de investigación. Hombre y Desierto 9: 225-245.

-1998. El patrimonio del valle de Santa María en peligro. En 50 años de aportes al desarrollo y consolidación de la antropología argentina. Homenaje a Alberto Rex González, pp. 205-253. Facultad de Filosofía y Letras. Fundación Argentina de Antropología, Buenos Aires.

-2000. Chacras y pucara. Desarrollos sociales tardíos. En Los pueblos originarios y la conquista, M. Tarragó (Ed.), pp. 257-300. Sudamericana, Buenos Aires.

TARRAGO, M. y L. R. GONZALEZ, 2000 Ms. La construcción social del espacio en Rincón Chico, Noroeste Argentino. Ponencia presentada en el $50^{\circ}$ Congreso Internacional de Americanistas, Varsovia.

TARRAGO, M. N. y M. C. SCATTOLIN, 1999. La problemática del Período Formativo en el valle de Santa María. Actas XII Congreso Nacional de Arqueología Argentina, pp. 142-153. La Plata.

TARRAGO, M., S. CAVIGLIA, M. PERALTA y J. SOSA, 1988 Ms. Los grupos cerámicos del poblado de Loma Rica de Shiquimil, Catamarca, Argentina. Ponencia presentada en el IX Congreso Nacional de Arqueología Argentina, Buenos Aires.

TARRAGO, M., L. R. GONZALEZ y J. NASTRI, 1997. Las interacciones prehispánicas a través del estilo: El caso de la iconografía santamariana. Estudios Atacameños 14: 223-242.

TARRAGO, M., L. R. GONZALEZ, P. CORVALAN, R. DORO, M. MANASIEWICZ y J. PEÑA, 1999. La producción especializada de alimentos en el asentamiento prehispánico tardío de Rincón Chico, provincia de Catamarca. Cuadernos del Instituto Nacional de Antropología y Pensamiento Latinoamericano 18: 409-427.

TARRAGO, M., L. R. GONZALEZ, M. TANCREDI, M. MANASIEWICZ, A. VARGAS y P. CAMPO, $2000 \mathrm{Ms}$. La ventana indiscreta: Variabilidad en los modos arquitectónicos incaicos. Un caso de estudio en el sur del valle de Yocavil. Ponencia presentada en el XV Congreso Nacional de Arqueología Chilena, Arica.

TARRAGO, M., L. R. GONZALEZ y M. TANCREDI, 2001 Ms. Nuevas evidencias incaicas en el sur del valle Yocavil. Actas XIV Congreso Nacional de Arqueología Argentina, Rosario.

TARRAGO, M., P. CAMPO, P. CORVALAN, R. DORO, M. MANASIEWICZ y V. PALAMARZUK, 2002. Análisis cerámico en sitios del bajo de Rincón Chico. Actas XIII Congreso Nacional de Arqueología Argentina, pp. 431445. Córdoba.

TEN KATE, H., 1896. Anthropologie des anciennes habitants de la Region Calchaquie (Republique Argentine). Anales del Museo de La Plata I: 1-62. 
WEISER, V., 1920 Ms. Diarios de campo 4a expedición. Museo de La Plata.

WILLIAMS, V., 1994. Jerarquización y funcionalidad de centros estatales incaicos en el área valliserrana central del NOA. Shincal 4: 11-34.
-2000. El Imperio inca en la provincia de Catamarca. Intersecciones en Antropología 1: 55-78.

WILLIAMS, V. y T. D’ALTROY, 1998. El sur del Tawantinsuyu: Un dominio selectivamente intensivo. Tawantinsuyu 5: $170-178$. 